ISSN: 0213-2079 - ISSN electrónico: 2386-3889

DOI: https://doi.org/10.14201/shhmo2017391327367

\title{
FRANCISCO DE BORJA EN EL ESPEJO DE TERESA DE JESÚS (VIDAS PARALELAS UNIDAS POR LA MODERNIDAD)
}

\section{Francisco de Borja in Teresa of Jesus' Mirror (Parallel Lives United by Modernity)}

Santiago LA PARRA LÓPEZ

Escuela Politécnica Superior de Gandía (UPV)

Correo-e: slaparr@har.upv.es

RESUMEN: El V centenario del nacimiento de Teresa de Jesús puede ser excusa propicia para reflexionar sobre las relaciones, efímeras pero muy intensas, de la santa de Ávila con Francisco de Borja. Nos hallamos ante dos personajes diferentes, protagonistas ambos de un tiempo convulso que cambió Europa, y que acabaron unidos por su sentido de la modernidad. La imagen de Borja que vemos reflejada en el corazón-espejo de la madre Teresa no es la de alguien anclado en el pasado medieval y esta conclusión constituye, por tanto, un argumento más para revisar la biografía del duque de Gandia, que fue santo sin renegar de su polémica familia.

Palabras clave: Teresa de Jesús; Francisco de Borja; Modernidad; monjas; jesuitas.

ABSTRACT: The fifth centenary of the birth of Teresa of Jesus is an appropriate occasion to consider her ephemeral but intense relations with Francisco de Borja. Although they were two different historical characters, both were protagonists of a troubled period that transformed Europe, and were united in their sense of modernity. The image of Borja we find reflected in Mother Teresa's heart-mirror do not depict the Duke of Gandia as someone stuck in the medieval past. This conclusion is, thus, one more

(C) Ediciones Universidad de Salamanca / ®@ Stud. his., H. ${ }^{a}$ mod., 39, n. 1 (2017), pp. 327-367 
SANTIAGO LA PARRA LÓPEZ

FRANCISCO DE BORJA EN EL ESPEJO DE TERESA DE JESÚS

(VIDAS PARALELAS UNIDAS POR LA MODERNIDAD)

reason to reexamine the biography of Francisco de Borja, who was a saint without renouncing to his polemical family.

Key words: Teresa of Jesus; Francisco de Borja; Modernity; Nuns; Jesuits.

«Estando una vez en las Horas con todas, de presto se recogió mi alma y pareciome ser como un espejo claro toda... y en el centro de ella se me representó Cristo...» (Vida, XL, 5).

\section{Retratos}

Cuando en 1971 Américo Castro se refería a los «grandes del espíritu en el siglo XVI» español citaba al dominico Luis de Granada, al agustino Luis de León, al carmelita Juan de la Cruz, al secular Juan de Ávila y, por supuesto, a la también carmelita Teresa de Jesús, pero no al jesuita Francisco de Borja ${ }^{1}$. Naturalmente, no vamos a discutirle nosotros a $\mathrm{D}$. Américo sus criterios de selección en este punto, pero no solo creemos que el duque de Gandia también tendría un hueco en esa constelación, sino que podría conformarse una red de afectos personales, devociones religiosas y vínculos literarios entre todos esos personajes en torno a Borja precisamente y con más razón todavía alrededor de la propia monja abulense, con quien Fr. Luis tuvo relación indirecta como editor de sus obras. Porque la verdad es que no solo no nos consta relación personal alguna, directa ni indirecta, del agustino conquense con Francisco de Borja, sino que no debía tener buena opinión de los jesuitas, en general, como sugiere el hecho de que en su edición de las obras teresianas (ejemplar, por lo demás) censurara los elogios a la Compañía en la autobiografía de Teresa (Vida, xxviII) y una alusión favorable a Loyola en Las moradas (cap. v) ${ }^{2}$. Con todo, la primera biografía de la santa abulense (Salamanca, 1590) la firmaría el jesuita Francisco de Ribera ${ }^{3}$.

No somos nosotros, desde luego, quienes abordamos por primera vez la intensa relación de la monja de Ávila con la Compañía de Jesús, en general, o con

1. Castro, A.: Teresa la santa y otros ensayos. Madrid, 1982, p. 33 (revisado en 1971, fecha de la Introducción, a donde corresponde la cita).

2. Zugasti, J. A.: Santa Teresa y la Compañía de Jesús (Estudio histórico-crítico). Madrid, 1914, donde se desvela el oportuno borrón que tapaba el no y cambiaba por completo el sentido de la famosa frase: «como yo creo que ellos [los jesuitas] no dirán mentira», en una carta de la santa (2.V.1582) a Jerónimo Reinoso.

3. Fita Colomé, F.: «Cuatro biógrafos de Santa Teresa en el siglo xvi: El Padre Francisco de Ribera, Fr. Diego de Yepes, fr. Luis de León y Julián de Ávila», BRAH, 67, 1915, pp. 550-561.

(C) Ediciones Universidad de Salamanca / ®@ Stud. his., H. ${ }^{a}$ mod., 39, n. 1 (2017), pp. 327-367 
SANTIAGO LA PARRA LÓPEZ

FRANCISCO DE BORJA EN EL ESPEJO DE TERESA DE JESÚS

(VIDAS PARALELAS UNIDAS POR LA MODERNIDAD)

alguno de sus miembros concretos en particular ${ }^{4}$. Aquí evitaremos adentrarnos en la apasionada espiritualidad teresiana, pues nuestro propósito actual es intentar explicar de qué manera pudo influir Borja en esa alma de la Santa, que ella misma describía transformada ocasionalmente en espejo y, sobre todo, intentar ver cómo se refleja la figura del duque jesuita en el espejo (alma) de la monja abulense.

No pretendemos, pues, abundar en la mística teresiana ${ }^{5}$. Nuestra tesis es que hablamos de dos personajes coetáneos, protagonistas de un tiempo de cambio y, por tanto, de incertidumbre, cuyas respectivas trayectorias vitales estaban llamadas en principio a no encontrarse, por ser paralelas, pero acabaron unidas por la modernidad $^{6}$. Somos perfectamente conscientes de que esto añade poco a la imagen de Teresa de Jesús, pero confiamos en que ayude a perfilar algo mejor la del santo duque de Gandia, que ha estado considerado (y en buena medida lo sigue siendo) un personaje de mentalidad y espiritualidad más próximas al pasado medieval que al humanismo de su tiempo. En las hagiografías de la santa abulense se insiste en que ella fue cautivada por el duque jesuita. Aquí no cuestionamos esa reacción de la madre Teresa (aunque lo lógico es pensar que el sentimiento de afecto fuera mutuo), pues reivindicamos una nueva imagen del Borja religioso, que es la que se ve reflejada en el corazón de la santa precisamente por haber acertado a ganar la confianza de una mujer humilde, inteligente y de espiritualidad muy profunda.

Creemos que ambos personajes eran distintos por fuera, pero mucho más parecidos por dentro de lo que se ha reseñado hasta ahora. Ya, de entrada, el aspecto físico de nuestros dos personajes lo conocemos mejor por las respectivas descripciones literarias, sobre todo el de él, que por obra plástica alguna. Dionisio Vázquez,

4. Además de la obra ya citada, J. A. Zugasti publicó otra con título homónimo, Santa Teresa y la Compañia de Jesús (Bilbao, 1914), cuyas partes $1^{\mathrm{a}}$ y $3^{\mathrm{a}}$ están dedicadas a rebatir las tesis revanchistas -según él- del exjesuita Miguel Mir en su Santa Teresa de Jesús, su vida, su espíritu, sus fundaciones. Madrid, 1912, 2 vols. Cfr. Dalmases, C. de: «Santa Teresa y los jesuitas. Precisando fechas y datos», AHSI, 35, 1966, pp. 347-378; Jorge, E.: «San Francisco de Borja y Santa Teresa de Jesús», Manresa, 178, 1974, pp. 43-64; Iglesias, I.: «Santa Teresa de Jesús y la espiritualidad ignaciana», Manresa, 54, 1982, pp. 291-313. El n. 342 del vol. 87 (2015) de Manresa conmemora el V centenario del nacimiento de la santa con los artículos, entre otros, de EgIDo, T.: «"La principal ayuda que he tenido". Santa Teresa y los de la Compañía de Jesús», pp. 5-16 y Ruiz Jurado, M.: «Santa Teresa y los jesuitas», pp. 17-28.

5. Cfr. Certeau, M.: La fábula mística. Siglos XVI-XVII. Madrid, 2006 (original en francés 1982) y La debilidad de creer. Madrid, 2006 (original en francés 1987) para el marco de las relaciones entre la modernidad y el cristianismo (en general) y la mística (en particular), a través de sus textos.

6. Imícoz Beunza, J. M.a: «Transformaciones del vínculo social. Una reflexión sobre los procesos de la modernidad», en Franco Rubio, G. y Pérez Samper, M. A. (eds.): Herederas de Clío. Mujeres que han impulsado la Historia. Madrid, 2014, pp. 277-296.

(C) Ediciones Universidad de Salamanca / ®@ Stud. his., H. ${ }^{a}$ mod., 39, n. 1 (2017), pp. 327-367 
SANTIAGO LA PARRA LÓPEZ

FRANCISCO DE BORJA EN EL ESPEJO DE TERESA DE JESÚS

(VIDAS PARALELAS UNIDAS POR LA MODERNIDAD)

confesor y protobiógrafo de Borja, da fe de que el P. Francisco no consintió en vida, ni aun estando ya medio moribundo en su lecho de muerte, que un pintor copiara discretamente su rostro, de modo que -asegura Vázquez-, aunque «hanse sacado en Roma y en España algunos retratos de su figura, mas no he visto hasta ahora ninguno que me muestre aquel venerable y authorizado aspecto que, con solo mirarle, ponía devoción y alegría» ${ }^{7}$. Y él mismo lo describe así, dejándose llevar por la admiración:

Fue el padre Francisco de Borja bien alto de cuerpo; de hermoso rostro, blanco y colorado; de agraciadas facciones y proporcionados miembros; la frente ancha, la nariz algo larga y aguileña, los ojos grandes y zarcos, la boca pequeña y los labios del color de la fina grana; era carilargo y también eran muy largos los dedos de las manos...

A partir de los 30 años, durante su virreinato en Cataluña (1539-1543), sufrió una espectacular transformación física, pues pasó de una llamativa gordura «borjana» a una extrema delgadez «franciscana» como consecuencia inevitable de una dieta rigurosísima (dejó prácticamente de comer) y los excesos penitenciales (apenas dormía), lo que lógicamente afectó a su salud.

Teresa de Jesús era una mujer guapa y ella lo sabía. Una de las muchas anécdotas que se le atribuyen (y no creemos que necesariamente fueran ciertas) recoge los piropos de un albañil o lo barata que le salió cierta escritura ante un notario admirador de su belleza. Francisco de Ribera reseña cómo, de camino a la fundación de Burgos y contando a la sazón más de 60 años, Teresa atajó de raíz la conversación sobre ella de dos carmelitas que la acompañaban, con estas palabras:

Tres cosas he oído que se han dicho de mí: primera, que en mi juventud era de buen parecer; segunda, que soy prudente y, tercera, lo que algunos van ahora propalando de mí: que soy santa. Las dos primeras me las creí quizás demasiado en otro tiempo, pero ya me confesé de esta vanidad. En cuanto a la tercera, no soy tan boba que ni siquiera una sola vez me la haya creído, aunque no sea más que un tantico ${ }^{8}$.

Por iniciativa del P. Jerónimo Gracián (Provincial a la sazón y su confidente) se hizo el único y muy conocido retrato de la monja en vida, que se conserva en el Carmelo de Sevilla. Es obra de Giovanni Narducci (Juan Narduch), un antiguo

7. Vázquez, D.: Historia de la vida del P. Francisco de Borja, Tercero General de la Compañía de Jesús, (c. 1586), edición crítica por La Parra, S. Gandía, 2012, p. 374 para esta y 373 para la cita siguiente.

8. Ribera, F. de: Vida de santa Teresa de Jesús. Salamanca, 1590, ed. de Pons, J., Barcelona, 1908, cit. de p. 464 (puntuación y acentuación son nuestras).

(C) Ediciones Universidad de Salamanca / ®@ Stud. his., H. ${ }^{a}$ mod., 39, n. 1 (2017), pp. 327-367 
SANTIAGO LA PARRA LÓPEZ

FRANCISCO DE BORJA EN EL ESPEJO DE TERESA DE JESÚS

(VIDAS PARALELAS UNIDAS POR LA MODERNIDAD)

franciscano italiano que acababa de hacerse carmelita (Juan de la Miseria) y que conoció a Teresa de Jesús en la casa madrileña de Leonor de Mascarenhas (antigua dama portuguesa de la emperatriz Isabel, con la que Borja coincidió en la corte) camino ambos, pintor y modelo, de Pastrana. El resultado fue muy decepcionante para la interesada, quien exclamó al verlo: «Dios te lo perdone, fray Juan, que me has... pintado fea y legañosa»?.

El propio Ribera nos dejó un prolijo retrato literario de la santa, quien «aun después de vieja, parecía harto bien», destacando los famosos tres lunares de la cara que todos encontraban tan graciosos («uno más debajo de la mitad de la nariz, otro entre la nariz y la boca, y el tercero debajo de la boca») y, desde luego, sin olvidar glosar la blancura de su piel, que era requisito imprescindible a la sazón de belleza femenina ${ }^{10}$.

\section{VidAS PARALELAS DE DOS PERSONAJES MUY DIFERENTES POR FUERA}

\subsection{Protagonistas de un mundo nuevo}

Teresa de Ahumada nació en Ávila el 28 de marzo de 1515 y murió en Alba de Tormes el 4 de octubre de 1582, víspera del 15 de dicho mes, tras aplicar la reforma gregoriana del calendario al uso ${ }^{11}$. Era, pues, cuatro años y medio más joven que Borja (Gandia, 28.X.1510) y vivió seis más que él (Roma, 1.X.1572). Muy pronto el Cepeda de la abuela paterna Inés (cristiana de Tordesillas) taparía el Sánchez del abuelo judío Juan (Juan Toledo en sus tiempos de mercader) ${ }^{12}$, para acabar siendo universalmente conocida por su antropónimo religioso.

Teresa de Jesús fue canonizada por Gregorio XV en 1622, junto con Isidro Labrador, Ignacio de Loyola ${ }^{13}$ y Pedro de Alcántara. Borja alcanzó ese mismo reconocimiento medio siglo después, en 1671, el mismo año que Fernando III, Felipe Benicio, Cayetano de Thiene (fundador de los teatinos), el dominico valenciano Luis Beltrán y Rosa de Lima, que fue la primera santa americana.

9. Ribera, F. de: Vida de santa Teresa..., p. 358 (nota 1).

10. Idem, pp. 357-358.

11. Pérez, J.: Teresa de Ávila y la España de su tiempo. Madrid, 2007, p. 141.

12. Durante algún tiempo los Cepeda fueron conocidos en Ávila como «los toledanos» (EgIDo, T.: El linaje judeoconverso de santa Teresa [Pleito de hidalguía de los Cepeda]. Madrid, 1986, p. 20).

13. El P. Ignacio Iglesias habla también de un paralelismo entre Teresa y Loyola, aunque sus trayectorias solo se cruzarían ahora, en el momento de la canonización, dando por sentado «la profunda raigambre cristiana» ( $\dot{e}$ ?) de los respectivos antecedentes familiares (IGLESIAs, I.: «Santa Teresa...», p. 294).

(C) Ediciones Universidad de Salamanca / ®@ Stud. his., H. ${ }^{a}$ mod., 39, n. 1 (2017), pp. 327-367 
SANTIAGO LA PARRA LÓPEZ

FRANCISCO DE BORJA EN EL ESPEJO DE TERESA DE JESÚS

(VIDAS PARALELAS UNIDAS POR LA MODERNIDAD)

Ambos, santa Teresa y san Francisco de Borja fueron, pues, personajes del Renacimiento y santos del Barroco. Los dos vivieron todo el reinado de Carlos V y gran parte del de Felipe II. Años difíciles, «tiempos recios» (como diría la santa); de cambios y, por tanto, de incertidumbres, asociados a un doble descubrimiento crucial: el del mundo y el del hombre (Jules Michelet) ${ }^{14}$. El viaje de Colón hizo, en efecto, el planeta más grande y diverso, mientras el Renacimiento reivindicaba el hombre y la naturaleza dejaba de ser un enigma, cuando no fuente de pecado, para convertirse en «Dios o casi lo mismo»: idem est natura quod Deus aut fere idem, escribía en 1431 L. Valla (De voluptate, I, 13).

En aquella sucesión de novedades (magnificadas muchas de ellas por los propios humanistas) no sería anecdótica la división de la Iglesia tras la Reforma protestante. Recientemente se ha señalado cómo la clausura de Trento (1563) separa el tiempo de los conquistadores del tiempo de los santos (más que de las santas) ${ }^{15}$. La imagen se nos antoja muy sugerente y perfectamente ajustada al caso de santa Teresa, pues siete de sus nueve hermanos de padre y madre se fueron a América y ella misma sería santa. Menos necesitados de buscarse la vida allende los mares, de los Borja solo tenemos constancia de que emigrara al Nuevo Mundo Juan, hijo natural de Fernando de Borja (sexto hijo de san Francisco), quien permaneció soltero pero tuvo ese hijo con doña Violante Matheu de Armendia ${ }^{16}$. Ironías del destino, los herederos de esta rama bastarda arraigada en Ecuador son hoy los únicos descendientes conocidos de los Borja históricos ${ }^{17}$.

Nuestros dos personajes no fueron conquistadores sino santos y, antes que eso, personas muy destacadas; verdaderos protagonistas de su tiempo, cuyas vidas acabaron cruzándose tras haber partido de puntos de salida casi antagónicos y siendo muy diferentes entre sí..., al menos por fuera.

14. Ruiz-Doménec, J. E.: Observando la Modernidad desde la Edad Media. Valencia, 1999 , p. 26.

15. Alabrús Iglesias, R. M. ${ }^{a}$ y García Cárcel, R.: Teresa de Jesús. La construcción de la santidad femenina. Madrid, 2015, en especial el cap. I: «La fábrica de santos».

16. Este Juan de Borja, legitimado por Felipe III en 1604, sería Presidente de la Audiencia del Nuevo Reino de Granada y falleció en Bogotá (1628) (SAlazar y Acha, J. de: «Una rama subsistente del linaje de Borja en la América española», Boletín de la Real Academia Matritense de Heráldica y Genealogía, 75, 2010, pp. 16-17. Cfr. GANGOTENA y Jijón, C. de: Genealogía de la Casa de Borja. Quito, 1932).

17. BAtLlori, M.: «El llinatge Borja del segle XIII al xvi», en La família Borja, vol. IV de su Obra Completa. Valencia, 1994, pp. 3-54, cfr. p. 49 (texto de 1972).

(C) Ediciones Universidad de Salamanca / ®@ Stud. his., H. ${ }^{a}$ mod., 39, n. 1 (2017), pp. 327-367 
SANTIAGO LA PARRA LÓPEZ

FRANCISCO DE BORJA EN EL ESPEJO DE TERESA DE JESÚS

(VIDAS PARALELAS UNIDAS POR LA MODERNIDAD)

\subsection{Una mujer (monja fundadora) y un hombre (duque jesuita)}

\subsubsection{Una mujer en un mundo de hombres}

La primera y fundamental diferencia entre ambos es obvia: Teresa era mujer y Borja varón. Vaya por delante que ni el uno acabó sus días como duque y Grande de España ni ella se comportó como se esperaba a la sazón que lo hiciera una mujer. Ambos - protagonistas de su tiempo, decíamos- rompieron moldes sociales y ninguno lo tuvo fácil. Mucho menos ella, quien partía en desventaja por su condición femenina para conseguir el propósito de ser ella misma y no lo que otros pretendieran que fuera por el mero hecho de ser mujer. No es extraño, por tanto, que en el $\mathrm{V}$ centenario de su nacimiento se haya glosado, con razón, el feminismo avanzado de Teresa que agiganta su figura. Una mujer que, como tal, estaba llamada a ser callada y sumisa y parece evidente que la santa abulense nunca calló lo que ella creyó que debía decir.

En este punto nos ha sorprendido mucho la opinión, en todo lo demás tan fundada, del profesor T. Egido cuando, a propósito de la ingente labor fundacional de la madre Teresa (1562-1582) cree necesario «matizar interpretaciones con muy poco de históricas y mucho de dogmáticas, cuales las de la marginación y la discriminación radical de las mujeres por el hecho de serlo» ${ }^{18}$. Lejos de dogmatismo alguno, a nosotros nos parece una clamorosa evidencia la marginación histórica de la mujer (hasta hace poco agravada por su olvido historiográfico), que no se inicia en la era moderna pero se institucionaliza entonces.

El nuevo «estado moderno», que se construía bajo la batuta de Maquiavelo, buscaba incrementar el poder real con el concurso del político «profesional» (formado en las universidades, que proliferan) y del nuevo militar experto en el manejo de la pólvora, diestro en la estrategia bélica y eficiente en la intendencia castrense. Para el nuevo político maquiavélico la ética era un obstáculo que había que apartar si interfería en la consecución de los fines propuestos, mientras que para el condotiero las Matemáticas y la Geometría le eran más útiles en campaña que la Teología.

Ese largo viaje hacia la modernidad incluía otras vías, tanto o más pragmáticas, como diferenciar entre lo público y privado. En este nuevo reparto de funciones y espacios a la mujer se le adjudicó, y no por azar ni por casualidad, el cuidado del hogar, con la obligación estratégica de parir soldados y criar contribuyentes para

18. EgIDo, T.: «"Mis amigos mercaderes” y gentes del común, colaboradores en las fundaciones de santa Teresa», Revista de Espiritualidad, 71, 2012, pp. 475-499, cit. de p. 477.

(C) Ediciones Universidad de Salamanca / ®@ Stud. his., H. ${ }^{a}$ mod., 39, n. 1 (2017), pp. 327-367 
SANTIAGO LA PARRA LÓPEZ

FRANCISCO DE BORJA EN EL ESPEJO DE TERESA DE JESÚS

(VIDAS PARALELAS UNIDAS POR LA MODERNIDAD)

el nuevo estado, a tiempo completo. Lo inmediato era, pues, justificar la clausura doméstica femenina: «los fundamentos de la casa -escribiría Fr. Luis en La perfecta casada $-^{19}$ son la mujer y el buey: el buey para que are y la mujer para que guarde» (cap. XVII). La esposa ejemplar debe ser sumisa y callada «porque -insistía Fr. Luis-, así como la naturaleza... hizo a las mujeres para que, encerradas, guardasen la casa, así las obligó a que cerrasen la boca» (cap. xvi).

Toda imposición que aspire a perdurar necesita de su correspondiente justificación teórica y no sería, desde luego, Fr. Luis de León el único en asumir esta tarea imprescindible para mantener y reproducir el nuevo orden social. Juan Luis Vives aportó a este fin toda su elocuencia, que no era poca, en su De officio mariti (1528), dedicado a su buen amigo D. Juan de Borja (padre del santo duque gandiense). Para entonces, en Institutio foeminae christianae (1523) el humanista valenciano había defendido la necesidad de la educación femenina, sí, pero dejando perfectamente asentado que «las dos cosas principales que ha de tener la mujer casada... son: castidad y amor entrañable al marido ${ }^{20}$. Bien entendido que, a la sazón, la exigencia de la castidad y honestidad era mucho mayor para la mujer que para el hombre porque, como el mismísimo Alejandro VI aconsejaba en 1493 vehementemente a su hijo Juan (II duque de Gandia y, como tal, abuelo de san Francisco), «la honor de les dones importa tota la honor del home e de la casa sua» ${ }^{21}$.

Tiene razón, pues, Joan Kelly cuando dictamina que no, que las mujeres no tuvieron Renacimiento ${ }^{22}$. Pero también es cierto que, como escribe Margaret L. King, «aunque en el Renacimiento no hubo cambios ni mejoras en la condición social de las mujeres, sí hubo un cambio en la idea que ellas tenían de sí mismas ${ }^{23}$. Y en esta misma línea concluye Romeo de Maio que, «aunque la condición de la mujer no cambió en el Renacimiento, se decidió entonces su futuro» ${ }^{24}$.

19. Salamanca, 1583. Citamos, por capítulos, según la versión de Austral, Madrid, 1975, 10. ${ }^{a}$ ed., (acentuación y puntuación nuestras).

20. Manejamos la versión de L. Riber en Obras completas. Madrid, 1947, cit. de I, 1.076.

21. SANCHis Sivera, J.: Algunos documentos y cartas privadas que pertenecieron al segundo duque de Gandia don Juan de Borja. Notas para la historia de Alejandro VI. Valencia, 1919, según ed. crítica en valenciano por La Parra, S. (revisión lingüística por García, V.). Gandía, 2001, p. 85. Esto concordaba perfectamente con lo que B. Castiglione preconizaba en El cortesano.

22. Kelly, J.: «¿Tuvieron las mujeres Renacimiento?», en Amelang, J. S. y Nash, M. (eds.): Historia y Género. Las mujeres en la Europa Moderna y Contemporánea. Valencia, 1990, 93-126, en especial 123 y 125 (original publicado en 1984).

23. KING, M. L.: Mujeres renacentistas. La búsqueda de un espacio. Madrid, 1993 (original en inglés, 1991), p. 297.

24. Maio, R. de: Mujer y Renacimiento. Madrid, 1988 (orig. en italiano, 1987), p. 9

(C) Ediciones Universidad de Salamanca / ®@ Stud. his., H. ${ }^{a}$ mod., 39, n. 1 (2017), pp. 327-367 
SANTIAGO LA PARRA LÓPEZ

FRANCISCO DE BORJA EN EL ESPEJO DE TERESA DE JESÚS

(VIDAS PARALELAS UNIDAS POR LA MODERNIDAD)

Teresa de Jesús, monja de clausura, participó destacadamente en esa lucha por la dignificación de la mujer en la vida social y religiosa; una lucha de siglos y que, pese a los muchos avances, no se puede dar hoy por acabada. Más allá de algún prejuicio muy extendido, la clausura femenina del mundo católico se presentaba paradójicamente como un reducto de libertad para aquellas mujeres que no estaban dispuestas a trocar la sumisión al padre por el sometimiento al marido y preferían el matrimonio místico con Cristo:

No sé cómo he de pasar de aquí [escribía la propia santa Teresa], cuando me acuerdo la manera de mi profesión y la gran determinación y contento con que la hice y el desposorio que hice con Vos (...) Para que más se vea quién Vos sois, Esposo mío, y quién soy yo (Vida, IV, 3 ).

Y no olvidamos que las monjas estaban bajo la tutela directa de un hombre -el confesor- y de la correspondiente institución masculina de la orden ${ }^{25}$ : «y la causa de no se haber fundado más ha sido el atarme los prelados en otra cosa» (Fundaciones, IV, 1).

Teresa padeció en carne propia todos esos prejuicios no solo en vida sino, de alguna manera, también después de muerta. Joseph Pérez remarca que en 1535, a sus 20 años de edad, eligió el convento porque la clausura le ofrecía más oportunidades de ser ella misma que el matrimonio. Hay que concluir lógicamente que su verdadera vocación religiosa, que no le llegó sino hasta los 40 años, fue más fruto de una construcción, de una búsqueda, un anhelo, que resultado de un momento de inspiración sobrevenida o de un soplo espontáneo. Como ella misma dejó escrito: «Y aunque no acababa mi voluntad de inclinarse a ser monja, vi [que] era el mejor y más seguro estado. $\mathrm{Y}$ así, poco a poco, me determiné a forzarme para tomarle» (Vida, III, 5 ).

No diremos que el hecho de ser mujer fuera la razón determinante para explicar el que, tras su muerte, no acabara cuajando ninguno de los tres intentos para designarla patrona de España, pero sí estamos convencidos de que su condición femenina no ayudó a consolidar el copatronato nacional, compartiéndolo con el Apóstol Santiago («hechura de España», según C. Sánchez Albornoz)²6. El

25. Amelang, J. S.: «Los usos de la autobiografía: monjas y beatas en la Cataluña moderna», en Amelang, J. S. y Nash, M. (eds.): Historia y Género. Las mujeres en la Europa Moderna y Contemporánea. Valencia, 1990, pp. 191-212; Schultz van Kessel, E.: «Vírgenes y madres entre cielo y tierra. Las cristianas en la primera Edad Moderna», en Duby, G. y Perrot, M. (dirs.): Historia de las mujeres, vol. III: Del Renacimiento a la Edad Moderna (coord. por Faroe, A. y Davis, N. Z.). Madrid 1992, pp. 167-209 (ed. original en italiano: 1990-92).

26. «Santiago hechura de España y no España obra de Santiago» es el título de uno de los epígrafes de su monumental y polémica España un enigma bistórico, I, 265-287.

(C) Ediciones Universidad de Salamanca / ®@ Stud. his., H. ${ }^{a}$ mod., 39, n. 1 (2017), pp. 327-367 
SANTIAGO LA PARRA LÓPEZ

FRANCISCO DE BORJA EN EL ESPEJO DE TERESA DE JESÚS

(VIDAS PARALELAS UNIDAS POR LA MODERNIDAD)

primero de estos nombramientos efímeros lo acordaron las Cortes de Castilla en 1617, cuando la madre Teresa era aún beata. En 1627, a los cinco años de su canonización, se retomó la iniciativa; el proceso, que resultó ahora más largo y complejo, contó con el favor del conde duque de Olivares y la decidida oposición de Quevedo (caballero de Santiago). El tercer y último paso en este sentido lo dieron los liberales de Cádiz, en 1812, con la mirada puesta en su objetivo de suprimir del Voto de Santiago ${ }^{27}$.

\subsubsection{Un hombre en un mundo de mujeres}

Contaba Dionisio Vázquez en su «protohagiografía» de Francisco de Borja que, siendo virrey de Cataluña (junio 1539-mayo 1543), su esposa Leonor de Castro decidió uno de esos años celebrar privada y exclusivamente la fiesta de la Invención de la Cruz ( 3 de mayo) con las damas de la nobleza barcelonesa en un apartado de la residencia virreinal. «Y embiaron a rogar al virrey que... no consintiesse que ningún cavallero entrasse donde estavan». Don Francisco, siempre complaciente con su esposa, optó por seguirle el juego con gusto «y alabó su consejo porque dezía y frisava con el recato y honestidad que él desseava en las damas». Pero la diversión estuvo a punto de terminar en escándalo mayúsculo cuando «llegó un cavallero mancebo, que era uno de los mayores Grandes de España, el qual acertó a estar aquellos días en Barcelona» y se empeñó en franquear la puerta que custodiaba el virrey. Se echó mano a las espadas, pero nadie llegó a desenvainar porque el anfitrión cedió a tiempo, venciendo las ganas de descargar toda su autoridad (que no era poca) contra aquel entrometido joven, a quien hizo ver «que no es servicio de Dios ni del emperador que, por causa tan liviana, nos perdamos aquí todos» ${ }^{28}$. Vázquez se servía de esta anécdota para incidir, una vez más, en la humildad de que hizo gala su admirado Borja desde antes incluso de entrar en religión. Y aderezaba su relato con un aditamento sobrenatural, asegurando que el suceso narrado fue percibido en tiempo real por las clarisas de Gandia, reunidas en oración a quinientos kilómetros de distancia.

Sin necesidad de recurrir a implicaciones milagrosas, se nos antoja muy elocuente la imagen de Francisco de Borja custodiando la estancia en la que se solazaba su esposa con las amigas, pues creemos que refleja con bastante fidelidad un aspecto

27. Rey Castelao, O.: «Teresa, patrona de España», Hispania Sacra, LXVII, 136, 2015, pp. 531-573, donde la autora estudia los flecos historiográficos de la cuestión hasta la actualidad. Cfr. Pérez, J.: Teresa..., pp. 271-275 y Alabrús, R. M. a y García Cárcel, R: Teresa..., pp. 131-133.

28. VÁzquez, D.: Historia de la vida..., pp. 172-173.

(C) Ediciones Universidad de Salamanca / ®@ Stud. his., H. ${ }^{a}$ mod., 39, n. 1 (2017), pp. 327-367 
que pasa desapercibido en las biografías al uso del santo duque de Gandia: estamos hablando de un Borja que, hasta su ingreso en religión, frecuentemente se movió en un contexto marcado por una muy relevante presencia femenina, mostrándose él siempre muy respetuoso con aquellas mujeres que lo rodeaban. Dicho esto mismo con la versión italianizada del apellido - «Borgia»- acaso destaque más el alcance de la sugerente paradoja que proponemos para entender mejor la etapa laica de la vida de nuestro protagonista. Bien mirado, la propuesta no debería extrañarnos si pensamos que el mismísimo Aquiles pasó su adolescencia en un gineceo y menos aún nos sorprendería si hubiéramos ya superado esa imagen tan al uso de la familia Borja-Borgia como sinónimo de escándalo, que ha acuñado una literatura mediocre y una historiografía tópica y banal ${ }^{29}$. En este punto, nos parece oportuno reiterar que Francisco de Borja no se desentendió de su estirpe, supuestamente avergonzado por tanta depravación, como viene sosteniendo la historiografía al uso, tanto la liberal como la más conservadora. Muy al contrario, fue él, precisamente él, quien impuso en su familia y corte ducal una actitud de reconocimiento positivo y agradecimiento expreso a sus antepasados, en general, con mención especial a su bisabuelo Alejandro VI, en particular, perfectamente consciente de que la Casa de Gandia le debía lo que era al segundo papa de la familia ${ }^{30}$.

Huérfano de madre siendo aún niño, Francisco no conoció a su abuela María Enríquez fuera del convento, pues ella ingresó en la clausura (1511) un año después del nacimiento de su primer y único nieto varón. Pero no pudo sustraerse a la impronta indeleble de aquella mujer excepcional, capaz de enfrentase al mismísimo Alejandro VI, su suegro, para hacerse cargo de la regencia del ducado de Gandia desde el alevoso asesinato de su esposo Juan (Roma, 1497) hasta la mayoría de edad de su hijo, también Juan. Como dejó escrito el P. Batllori, «Maria Enriquez... donà un caire d'espiritualitat franciscana al Palau de Gandia, que ja era prou deshonorat per greus escàndols des del temps dels ducs pertanyents a la casa real de Catalunya-Aragó»" ${ }^{31}$. Desde el convento, la potente sombra de su abuela debió

29. Hermann-Röttgen, M.: La familia Borja. Historia de una leyenda. Valencia, 1994 (original en alemán, 1992); nuestro punto de vista al respecto lo explicamos en «La mirada sobre los Borja. (Notas críticas para un estado de la cuestión)», Revista de Historia Moderna. Anales de la Universidad de Alicante, 15, 1996, pp. 387-401.

30. Esta tesis la explicamos con más detalle en: «El ducado de Gandía y la memoria familiar de san Francisco de Borja», Revista de l'Institut Internacional d'Estudis Borgians, 2: Actes del II Simposi Internacional sobre els Borja (Valencia-Gandia, 2007), ed. electrónica: http:// personales.upv.es/slaparr/Artículos/183569-236404-1-PB.pdf

31. Batllori, M.: A través de la història i la cultura. Barcelona, 1979, 190. A falta de la urgente biografía de esta mujer verdaderamente singular, $c f r$ nuestra apretada contribución con la voz «Enríquez, María» en el vol. XVII del Diccionario Biográfico Español. Madrid, 2011.

(C) Ediciones Universidad de Salamanca / ®@ Stud. his., H. ${ }^{a}$ mod., 39, n. 1 (2017), pp. 327-367 
de contribuir a paliar la pérdida temprana de la madre, Juana de Aragón y Gurrea, quien falleció cuando Francisco apenas contaba 10 años. Tras esta temprana orfandad de madre, su vida laica transcurrió al servicio de las mujeres de su casa. Pasó su infancia rodeado de niñas, pues de sus seis hermanos, de padre y madre, cuatro eran chicas y parece que mantuvo siempre una especial relación con Luisa, la mayor y muy probablemente la única de entre sus hermanas que manifestó una clara vocación de monja y, no obstante eso, la casaron con el duque de Villahermosa $^{32}$. Por contra, de sus trece hermanos de padre (contando al bastardo Juan Cristóbal) solo tres eran mujeres.

Su madrastra Francisca de Castro Pinós acaso represente la excepción a las cordiales relaciones de Francisco con las mujeres de su entorno, pues el poco trato directo que tuvo con ella no se puede decir que fuera muy afable. Ya, de entrada, lo primero que hizo en cuanto tomó posesión efectiva del ducado de Gandia (mayo 1543) fue interponer ante la Audiencia un pleito contra ella, pretendiendo injustificadamente (de acuerdo con el fallo del alto tribunal) que Francisca asumiera parte de las deudas del fallecido duque.

Este segundo matrimonio de su padre se había celebrado en 1523, pero Francisco no pudo asistir a la boda porque desde el año anterior estaba en Tordesillas sirviendo como menino a Juana la Loca. Allí permaneció hasta 1525, cuando la infanta Catalina, tres años mayor que él y su compañera de juegos, marchó a Portugal para casarse con el futuro Juan III. Su amistad con esta infanta de España y reina de Portugal resistió las durísimas tensiones diplomáticas hispano-lusas ${ }^{33}$ (que terminaron con la anexión de Portugal por Felipe II) y se prolongó cuando él ya era jesuita y ella la reina-abuela de Portugal, como viuda de Juan III y tutora de su nieto, el mítico D. Sebastián.

Borja volvería a la corte en 1528, para ganar méritos que añadir a la herencia del ducado, con la clara conciencia de que el futuro de las familias nobles quedaba tanto más garantizado cuanto más cerca se estuviera del rey. Pronto se ganó la plena confianza del emperador (quien lo designaría uno de sus albaceas) y estuvo al servicio directo de otra mujer, la propia emperatriz en este caso, como su caballerizo mayor. Isabel de Portugal lo casó con una de sus damas, Leonor de Castro, contra la opinión de don Juan de Borja, quien prefería como nuera una noble de la corona aragonesa. Desde el primer instante Francisco transigió con esta boda, la suya, y quede aquí solo apuntado que las intrigas de Leonor de Castro contra Juan III de Portugal, en connivencia con el obispo de Viseo, arruinaron la carrera

32. Muniesa, T.: Vida de la V. y Exma. Sra. D. Luisa de Borja y Aragón, Condesa de Ribagorza... Zaragoza, 1691.

33. Fernández Álvarez, M.: Carlos V, el César y el Hombre. Madrid, 1999, p. 834.

(C) Ediciones Universidad de Salamanca / ®@ Stud. his., H. ${ }^{a}$ mod., 39, n. 1 (2017), pp. 327-367 
política de su marido, frustrando el nombramiento del flamante IV duque de Gandia como nuevo mayordomo mayor del príncipe Felipe cuando este iba a casarse con María Manuela de Portugal (hija de Juan III y de Catalina de Austria). Leonor, en efecto, no debía ser mujer de trato fácil y, de hecho, el P. Batllori daba por sentado que «aquel matrimonio no pudo ser muy feliz» ${ }^{34}$, lo cual corrobora E. García Hernán ${ }^{35}$. No obstante, Francisco siempre mantuvo en este delicado punto una discretísima resignación y con esta misma predisposición aceptó el que, tras la muerte de su esposa (27.III.1546), los asuntos domésticos de su casa los dirigiera su cuñada Juana de Meneses.

Uno de los aspectos que destacaba Dionisio Vázquez de la estancia en la corte de su biografiado sería precisamente «la virginal vergüença y modestia con que tratava con las damas de palacio y señoras de la corte», a las cuales no visitaba sin previamente colocarse un cilicio "por huir todas las occasiones de offender a Dios». El biógrafo aclaraba que este detalle tan íntimo se lo había desvelado el canónigo Villalón, quien a su vez lo conocía por uno de los camareros de Borja ${ }^{36}$. Aunque el texto de Vázquez permaneció inédito por el veto del General Claudio Acquaviva, el manuscrito circuló profusamente, sobre todo entre la familia ducal gandiense (también llegó a otras manos, como las de Ribadeneyra, por ejemplo) $y$, por tanto, no es de extrañar que Tomas de Borja (el medio hermano menor de Francisco) declarara en el proceso de beatificación de su hermanastro que «cuando tenía que visitar algunas damas se ponía un cilicio. Por eso se cree que llegó virgen al tálamo» ${ }^{37}$.

Somos perfectamente conscientes de lo tentador que puede llegar a ser, sobre todo para los freudianos, el sacar conclusiones de tipo patológico a partir de un conocimiento tan superficial de este tipo de intimidades. Pero el asunto no requiere un análisis clínico sino histórico y, por tanto, el diagnóstico corresponde al historiador, no al médico. Y para no rehuir ninguna cuestión polémica, intentaremos apuntar nuestro punto de vista al respecto, de la manera más breve posible por

34. Batllori, M.: «Carlos V y la Compañía de Jesús», Estudios Carolinos. Cuarto centenario del emperador Carlos V. Curso de conferencias (octubre-diciembre 1958). Universidad de Barcelona, 1959, pp. 133-148, cit. de p. 143.

35. García Hernán, E.: "Algunos aspectos de la biografía de san Francisco de Borja», en Callado Estela, E. (coord.): Valencianos en la Historia de la Iglesia. Valencia, 2008, II, pp. 11-135.

36. VÁzquez, D.: Historia de la vida..., p. 134. Esta actitud de F. de Borja se emplazaría en las antípodas de los inverosímiles amoríos con la propia emperatriz que los autores románticos se inventaron, sin fundamento alguno, como haría, por ejemplo, El duque de Rivas en $E l$ solemne desengaño.

37. Dalmases, C.: El Padre Francisco de Borja. Madrid, 1983, p. 13.

(C) Ediciones Universidad de Salamanca / ®@ Stud. his., H. ${ }^{a}$ mod., 39, n. 1 (2017), pp. 327-367 
razones de espacio. Hay que partir de la base de que, como no podría ser de otra forma, Borja veía este y el resto de los asuntos de su entorno a través de las lentes de su tiempo, que dejaban apenas un resquicio minúsculo para las relaciones entre sexos. No insistiremos en el pensamiento misógino de los humanistas, en perfecta consonancia con la tradición judeocristiana, por una parte, y el clasicismo por el lado pagano. Eva y Pandora. No parece necesario abundar en esto, pero sí evocaremos dos casos concretos solo para ilustrar con ejemplos sencillos el alcance de la estrechísima moral sexual de la época y hasta dónde podía llegar a condicionar los comportamientos personales. El primero será para recordar los problemas que causaron los olores durante el traslado del féretro con los restos de Isabel de Portugal desde Toledo a Granada, en plena primavera castellana (1-16 de mayo), porque la emperatriz había dispuesto en su testamento que no quería ser embalsamada para que ningún varón accediera a su cuerpo desnudo ni aun después de muerta ${ }^{38}$.

El segundo ejemplo se refiere a las precauciones tomadas por nuestro Borja el día de la boda de Isabel, su hija mayor, con don Francisco Gómez de Sandoval y Rojas, marqués de Denia y conde de Lerma (padres del famoso valido de Felipe III). Según Vázquez (quien dice basarse en lo que le contó el propio marqués de Denia), firmadas ya las capitulaciones matrimoniales, don Francisco citó en Gandia a su futuro yerno cierto día a una hora determinada

Y él vino con mucho acompañamiento a la hora que su suegro le había ordenado y halló al duque a la puerta de Gandia, que le estava aguardando. Y saludado que le huvo, le llevó a la iglesia mayor assí, como venía de camino, sin permitir que se apeasse en palacio ni hablasse ni viesse a doña Isabel. Y desde la iglesia embió por la esposa a palacio y, llegada, la desposó luego, como estava concertado. Y al mismo punto se començó la missa con gran solennidad y en ella se velaron. Y desde la iglesia los llevó a su casa y se hizieron las fiestas del casamiento ${ }^{39}$.

Para avanzar una explicación a ese proceder de Borja en la corte, tan llamativo por escrupuloso, habría que empezar, antes que nada, por tener en cuenta que muy probablemente la principal cualidad de Borja no fuera su habilidad para las relaciones sociales. A nosotros nos parece que de su bisabuelo Alejandro VI heredó, por ejemplo, el sentido del ahorro (por no decir tacañería compulsiva), pero no el don de gentes (sin que esto quiera decir, ni muchísimo menos, que fuera huraño)

38. Alvar Esquerra, A.: La emperatriz. Isabel y Carlos V: amor y gobierno en la corte española del Renacimiento (1503-1539). Madrid, 2012, pp. 337-350. Pasaremos por alto la extraordinaria ligereza de este juicio del autor en p. 350: «su inmensa gordura [de F. de Borja], como la de su esposa, no nos hablan, precisamente, de personalidades equilibradas» ( $\dot{\imath}$ ?).

39. VÁzquez, D.: Historia de la vida..., p. 195. 
$y$, en consecuencia, estamos convencidos de que no fue precisamente lo que hoy diríamos un cazatalentos, como tampoco nos parece que hubiera podido ser un buen jefe de personal (a diferencia muy notable de Loyola, por ejemplo, en lo uno y lo otro). No es lo mismo observar a las personas desde la atalaya de un Grande de España-Borja, para más señas- que a la misma altura de los ojos. Pero mucho más importante que esta falta de habilidades sociales (según nuestra percepción) es la constatación del arraigadísimo sentido de la responsabilidad que caracteriza la trayectoria vital de Francisco de Borja en todas y cada una de las etapas que jalonan su biografía: como cortesano, esposo y padre, virrey, duque o jesuita y nos lo imaginamos (pues no tenemos datos concretos) como niño muy formal ${ }^{40}$. Nuestro Borja sería el actor perfecto en El gran teatro del mundo calderoniano. Este acendrado sentido de la responsabilidad personal resulta elemento novedoso en aquella estructura social del Antiguo Régimen, que anteponía los derechos de la colectividad (estamento, gremio o cofradía) a los del individuo, y deviene rasgo muy elocuente de la modernidad.

No nos parece, en fin, que Borja le tuviera miedo a las mujeres o las rehuyera (asunto que subyace aquí) sino que, muy al contrario, su concepto del honor y de la honra le inducía a guardar las formas escrupulosamente, a la vez que ese sentido de la responsabilidad personal que tenía tan asumido le obligaba a respetar a las mujeres, en general, y a su esposa, muy en particular, en todo y pese a todo (que no era poco en el caso de su cónyuge). Nos hallamos, pues, ante un primer rasgo de la modernidad de Borja, que no tiene nada que ver con fanatismos atávicos ni con traumas o complejos sexuales no superados. Porque, además y definitivamente, no acertamos a explicarnos de qué manera una persona acomplejada y patológicamente reprimida hubiera podido acceder al espejo (alma) de una Teresa de Jesús y mucho menos aún que ella le hubiera abierto su alma (espejo) como hizo con el duque jesuita.

\subsection{El peso del apellido y los sentidos de la fama}

El peso del apellido fue enorme para nuestros dos protagonistas, pero por razones muy diferentes. Baste recordar que, por parte de madre, Borja era nieto

40. Como no nos podemos detener aquí y ahora en ese arraigadísimo sentido de la responsabilidad que, según nosotros, caracterizaría el comportamiento de Borja (que insistimos en calificar de crucial, pese a que haya pasado desapercibido a todos sus biógrafos), sugerimos el siguiente ejercicio, a título de mero ejemplo y solo como piedra de toque: intentar explicar, sin esta precaución, todas las circunstancias de su nombramiento como caballero de Santiago, comenzando por el hecho mismo de que la concesión se hiciera a petición propia...

(C) Ediciones Universidad de Salamanca / ®@ Stud. his., H. ${ }^{a}$ mod., 39, n. 1 (2017), pp. 327-367 
de un arzobispo y bisnieto de un rey (Fernando el Católico), mientras que su bisabuelo paterno era ni más ni menos que el papa Alejandro VI y, en consecuencia, él era sobrino-nieto de César y Lucrecia Borja. Tal cual.

Muy al contrario, ya sabemos que Juan Sánchez, abuelo paterno de Teresa, fue reconciliado tras confesar su judaísmo ante el Santo Oficio (20.VII.1485), aprovechando un edicto de gracia y adelantando una generosa cantidad de dinero. Ese paso decisivo en la limpieza de su linaje fue ratificado con la concesión de una hidalguía local sobre Ávila, Hortigosa y Manjabálago -hidalguía «de gotera», pero hidalguía al cabo- por sentencia de la Chancillería vallisoletana (26.VIII.1522) tras un pleito que transcurrió en plena revuelta comunera ${ }^{41}$. Bien es verdad que la fe judaica del viejo comerciante toledano debía estar ya muy matizada a la sazón tras su matrimonio con una cristiana vieja (Inés de Cepeda) y por esta misma condición religiosa de una de sus nueras ${ }^{42}$. Es obvio que tales antecedentes no ayudarían mucho, pero tampoco serían bastantes por sí mismos para explicar el hecho cierto de que la familia fuera muy a menos tras que el padre, Alonso Sánchez, dilapidara la hacienda familiar y las respectivas dotes de sus dos matrimonios (con la pudiente Catalina del Peso en 1505 y con Beatriz de Ahumada en 1509) para «morir en la más profunda miseria» ${ }^{43}$.

A nosotros nos parece que ni Borja ni Teresa sucumbieron al peso de sus respectivos pasados familiares, tan diferentes. Pero así como ella salió indemne y aun reforzada del trance, creemos que no se puede decir lo mismo del duque jesuita, cuya memoria sigue marcada por la mala fama de su apellido. Mala fama por lo que se cuenta de sus antepasados y por cómo se cuenta, que no parece sino un juicio sumarísimo con pena máxima de antemano y el agravante de que cualquier intento de reconducir el relato de la historia familiar por los cauces de la crítica histórica debe comenzar por pedir excusas y aclarar explícitamente que no, que la pretensión no es trocar la leyenda negra por otra nueva de color rosa, como si sobre los Borja solo pudiera escribirse cuentos; de terror o de hadas, pero cuentos. En esa construcción tópica y banal, el papel asignado al duque santo de Gandia es el de mero contrapeso, oportuno clavo que saca otro clavo; puro instrumento, en definitiva, al servicio de un tópico, que es imagen tan simplista y castrante como la de la depravación intrínseca de sus antepasados italianizados. Y no es cuestión

41. EgIdo, T.: El linaje judeoconverso..., pp. 23-28.

42. Alabrús, R. M. ${ }^{a}$ y García Cárcel, R.: Teresa..., pp. 153-160 y más concretamente p. 157.

43. EgIDo, T.: «Santa Teresa y su obra reformadora», Historia 16, 78, 1982, pp. 43-50, cit. de p. 44.

(C) Ediciones Universidad de Salamanca / ®@ Stud. his., H. ${ }^{a}$ mod., 39, n. 1 (2017), pp. 327-367 
de simpatías personales ni (ya se nos olvidaba) de cambiar el color de la leyenda sino de respeto a Clío y sus leyes.

Por eso nos parece que la fama de la monja abulense (pese a los avatares del pleito de hidalguía de su abuelo) ha resistido mucho mejor que la del jesuita valenciano los envites de la manipulación, incluido el uso (hasta morboso en ocasiones) que se ha hecho siempre de sus reliquias, como explica con lucidez y precisión Joseph Pérez en su citada biografía. Muy probablemente el origen geográfico de nuestros dos protagonistas no tenga nada que ver con su diferente consideración en la memoria colectiva, pero tampoco podemos dejar de pensar que la condición de valencianos de los Borja no les favoreció nunca, ni en vida ni, sobre todo, a la hora de su recuerdo. Entre otras razones porque estamos convencidos de que el mayor pecado de ambos papas valencianos (Alfonso y Rodrigo Borja) no fue su conducta moral sino su condición de «extranjeros» (léase: no italianos) en el Vaticano, como tampoco creemos que los escándalos (reales e inventados) atribuidos a Alejandro VI fuera lo más original de su pontificado. Pero eso, insistimos, entre otras razones...

Sea como quiera, una de las cosas que a nuestros ojos hacen más grandes a nuestros dos personajes, Teresa de Jesús y Francisco de Borja, es la dignidad con la que ellos mismos sobrellevaron el peso de su apellido. Una vez más, sus admiradores y detractores han sido más papistas que el papa (tentación que se hace muy difícil de evitar, por cierto, al hablar de Alejandro VI); unos y otros han abusado del «pathos» en detrimento del «logos» y el perdedor, como siempre, es el «ethos». En el caso concreto de santa Teresa, su gran amigo y confidente P. Jerónimo Gracián dejó constancia de su lógica reacción de incomodidad o, por qué no, de enfado (ella aspiraba a ser monja de carne y hueso y, por tanto, también se enfadaba) cuando en cierta ocasión él aludió a su linaje, apresurándose a aclararle «que le bastaba con ser hija de la Iglesia Católica» ${ }^{44}$. Teresa de Jesús siempre se comportó como una monja en el mundo, no como una santa en el altar, y este tipo de reacciones suyas nos hacen mucho más llevaderas las hagiografías. Porque la fama no es solo el juicio de un comportamiento sino también cómo se cuenta.

En cuanto a san Francisco, no insistiremos más en su orgullo expreso por unos antecedentes (y consecuentes) familiares tan ilustres. Pero lo novedoso, lo que lo hace grande y, de nuevo, avanzado a su tiempo sería la valoración de los méritos propios por encima de los honores heredados: Quae utilitas in sanguine meo dum descendo in corruptionem?, gustaba repetir evocando el salmo 29. Dionisio Vázquez relata que esta fue la respuesta que dio el P. Francisco (sin duda que con

44. Cit. por Castro, A.: Teresa..., p. 26.

(C) Ediciones Universidad de Salamanca / ®@ Stud. his., H. ${ }^{a}$ mod., 39, n. 1 (2017), pp. 327-367 
segundas intenciones) cuando, tras una sangría, un hermano de la Compañía le mostró su extrañeza porque su sangre fuera del mismo color que la de los plebe$\operatorname{yos}^{45}$. El P. Borja dejó bien arraigada en su familia (que es donde primero tenía que sembrar esa idea) la reivindicación del mérito personal por encima del linaje, como lo evidencia el hecho concreto de hallar dicha cita del salmo en la filacteria que porta un ángel, con el alma del santo duque camino del cielo, en una de los techos de la Galería Dorada u Obra Nueva del palacio ducal de Gandia, que fue la última aportación borgiana a este inmueble señorial, realizada por D. Pascual Francisco de Borja y Ponce de León, X duque de Gandia, para celebrar la canonización de su bisabuelo Francisco ${ }^{46}$.

\section{Dos Personajes unidos por la Modernidad}

\subsection{Encuentro en Ávila}

José Segrelles pintó en 1956 a santa Teresa y san Francisco en una de las tablas del retablo de la capilla del Sagrario que se venera en la iglesia del palacio ducal de Gandia ${ }^{47}$. Llama la atención el caso porque no abundan los testimonios iconográficos de ambos personajes juntos (que aquí más bien aparecen yuxtapuestos). No es extraño que así sea, pues solo mantuvieron dos encuentros personales, ambos en Ávila, pero, eso sí, tan intensos que fueron suficientes para cimentar una estrecha relación de por vida basada en la admiración y respeto mutuos.

Con todo, más llamativa puede resultar la ausencia de noticias de este feliz encuentro en la biografía del santo duque de Gandia escrita por Dionisio Vázquez, que inspiró -y aun mucho más que eso- las hagiografías posteriores de sus correligionarios, los Padres J. E. Nieremberg, P. Ribadeneyra y del mismo A. Cienfuegos. Este vacío informativo no se explica solo por el hecho cierto de que Vázquez no acompañara a Borja en 1557 cuando se entrevistó con la santa abulense, sino por otra razón de más peso y menos objetiva. Vázquez fue destinado a Ávila precisamente el año siguiente, 1558, como nuevo director del flamante colegio de la

45. Vázquez, D.: Historia de la vida..., p. 423.

46. Cervós, F. y SolÁ, J. M.a.: El palacio ducal de Gandía. Monografía histórico-descriptiva. Barcelona, 1904 (hay edición facsímil, con prólogo de Revuelta González, M. Gandia, 2004). Cfr. La Parra, S.: La ruta valenciana de los Borja. Gandia, 1997.

47. García Mahíques, R.: «El concepto icónico de san Francisco de Borja, elaborado por los jesuitas a partir de la adquisición del palacio ducal de Gandía», en LA PARRA, S. y Toldrà,

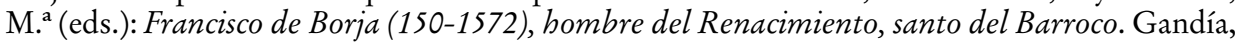
2012, 497-516, cfr. pp. 513 y 515.

(C) Ediciones Universidad de Salamanca / ®@ Stud. his., H. ${ }^{a}$ mod., 39, n. 1 (2017), pp. 327-367 
SANTIAGO LA PARRA LÓPEZ

FRANCISCO DE BORJA EN EL ESPEJO DE TERESA DE JESÚS

(VIDAS PARALELAS UNIDAS POR LA MODERNIDAD)

Compañía que acababa de fundarse. Aquí permaneció hasta que fue sustituido en el cargo por el P. Gaspar de Salazar en 1561. Conocido el proverbial mal carácter de Dionisio Vázquez ${ }^{48}$, no nos sorprende que no acabara de adaptarse ni al colegio (con muchos problemas de inicio) ni a la ciudad y que sus estancia no resultara, por tanto, precisamente feliz. Pero lo que ahora más nos interesa es que, al decir del P. Dalmases, durante ese tiempo «se mostró poco afecto a Teresa de Jesús» ${ }^{49}$ y esto podría explicar que la ausencia en su relato del encuentro que ahora nos ocupa no fuera fruto del olvido ni mera casualidad.

Borja, que no se parecía en nada Dionisio Vázquez, visitó Ávila en tres ocasiones ${ }^{50}$. Durante la primera, que se prolongó desde mayo a septiembre de 1531, es muy posible que Teresa viera de lejos al entonces cortesano corpulento que acompañaba como caballerizo mayor a la emperatriz y al príncipe Felipe niño (el emperador se hallaba ausente, como era usual), pero obviamente no pudo hablar con él y menos aún a partir del 16 de julio, cuando su padre la internó provisionalmente en el convento de Nuestra Señora de Gracia. En 1554, recién nombrado comisario de la Compañía en la península Ibérica, volvió a la ciudad castellana para visitar las obras del colegio de San Gil, que él mismo había promocionado; Borja predicó a la sazón en la catedral, pero tampoco ahora pudieron verse, pues ella estaba ya en la clausura desde 1535. La tercera fue durante la Semana Santa y Pascua de 1557 y ahora, por fin, hablaron dos veces. Borja le pareció a la monja «un gran contemplativo» (Camino de Perfección, xxxi, 5) y este elogio multiplica su valor viniendo de quien venía. La impresión mutua resultó muy agradable e indeleble ${ }^{51}$, como sugiere el hecho, que no ha pasado desapercibido, de que las dos únicas alusiones personales que cita la santa en su autobiografía sean precisamente el «padre Francisco» (Vida, xxiv, 3) y, más repetidamente, el «santo hombre y de gran espíritu» Pedro de Alcántara (Vida, xxviI, 3, «passim»). Borja y Teresa no volverían a encontrarse nunca más, pero cultivaron su estrecha relación a través

48. Cfr. nuestro «Estudio introductorio: un polémico autor para una obra pionera e inédita», en Vázquez, D.: «Historia de la vida...», pp. 13-113.

49. Dalmases, C. de: voz «Vázquez, Dionisio», en Diccionario Histórico de la Compañía de Jesús. Biográfico-temático, dirig. por O’Neill, Ch. E. y Domínguez, J. Madrid, 2001, 4 vols.

50. Jorge, E.: «San Francisco de Borja y Santa...»; TAPia Sánchez, S. de: «Ávila, la ciudad que conoció Santa Teresa», Salamanca. Revista de Estudios, 59, 2014, pp. 27-44.

51. Según el combativo exjesuita Miguel Mir, «esta conferencia de Santa Teresa con el santo Duque de Gandia hubo de causar en ella efecto extraordinario»; y añade poco más adelante: «estas dos entrevistas nunca las olvidó la Madre Teresa de Jesús; tampoco las olvidó San Francisco de Borja, antes conservó de ellas los mejores recuerdos, hablando siempre que tenía ocasión de las virtudes y buen espíritu de su antigua penitente, a quien veneraba como a santa» (Mir, M.: Santa Teresa..., I, pp. 251 y 252, respectivamente).

(C) Ediciones Universidad de Salamanca / ®@ Stud. his., H. ${ }^{a}$ mod., 39, n. 1 (2017), pp. 327-367 
SANTIAGO LA PARRA LÓPEZ

FRANCISCO DE BORJA EN EL ESPEJO DE TERESA DE JESÚS

(VIDAS PARALELAS UNIDAS POR LA MODERNIDAD)

de un intenso intercambio epistolar. Por desgracia esas cartas se han perdido, pero nos consta que existieron, entre otras pruebas, por el testimonio positivo de sor Isabel de Santo Domingo (priora del Carmelo de Zaragoza en 1595) en el proceso de canonización de la madre Teresa ${ }^{52}$.

Es evidente, pues, que entre aquellas dos personas, de características personales y condición social tan diferentes, debía haber alguna afinidad tan fuerte que hiciera posible su rápido entendimiento y entrañable amistad de por vida. La explicación más coherente de esta fácil relación sería, en nuestra opinión, lo que podríamos denominar comunión de ambos con el espíritu de la modernidad, como no podría ser de otra manera entre quienes hemos considerado protagonistas de su tiempo. Algunos de los rasgos de esa modernidad que les atribuimos ya nos han salido al encuentro. Es el caso muy significativo, por ejemplo, de la nítida conciencia que tenía Borja de la responsabilidad personal, lo que implica la reivindicación del individuo con el corolario lógico de anteponer los méritos propios a los heredados. Esta mentalidad facilitaba el entendimiento con el espíritu místico de santa Teresa. Como escribía Américo Castro, «el fenómeno místico no puede explicarse sino como fruto de la inquietud individualista de la época renaciente ${ }^{53}$ y García de la Concha, por su parte, confiesa que

si tuviera que concretar cuál es a mi juicio el logro más revolucionario del planteamiento teresiano de la comunicación, yo no dudaría en apuntar a lo que de hecho constituye su más directo entronque con la modernidad renacentista: la valoración de la experiencia personal consagrada como punto de partida y eje de aquell ${ }^{54}$.

A la pregunta de qué es ser moderno Ortega respondía que mientras el hombre medieval se resignaba a asumir el mundo tal como es, en cuanto que creación divina, «el moderno cree que puede suprimir realidades y construir el mundo a su gusto en nombre de una idea ${ }^{55}$. Si admitimos que ser moderno es aspirar a cambiar el mundo, Teresa de Jesús y Francisco de Borja fueron adalides de la modernidad. Ellos acabaron siendo rompedores con el futuro que las circunstancias históricas les habían asignado, comportándose como dueños de sus respectivos destinos. $\mathrm{Ni}$ qué decir tiene que esto no fue fácil para ninguno de los dos. Sobre todo para ella, aunque también es cierto que Loyola, siempre pragmático, le recomendó al

52. Jorge, E.: «San Francisco de Borja...», p. 63.

53. Castro, A.: Teresa..., 54.

54. García de la Concha, V.: «Un nuevo estilo literario», Historia 16, 78, 1982, pp. 51-58, cit. de p. 54 (la cursiva es nuestra).

55. Ortega y Gasset, J.: «Renacimiento y retorno», en En torno a Galileo. (Esquema de la crisis). Madrid, 1982 (1933), p. 209.

(C) Ediciones Universidad de Salamanca / ®@ Stud. his., H. ${ }^{a}$ mod., 39, n. 1 (2017), pp. 327-367 
duque de Gandia que se anduviera con mucho tiento a la hora de hacer pública la decisión de cambiar la corona ducal por la tonsura clerical porque «el mundo no tiene orejas para oír tal estampido».

Teresa de Ahumada se hizo monja (pese a sus antecedentes judaizantes) y revolucionó la clausura. Sus conventos no debían ser «refugio» donde esconderse o «retiro» obligado para mujeres, sino ámbito de realización femenina; ella no quería que sus hijas carmelitas huyeran del mundo, sino que intentaran hacerlo más habitable desde el cenobio, alimentando el cuerpo con su trabajo y el alma con la oración íntima; el nuevo Carmelo no debía ser un lugar triste, sino de trabajo y oración reflexiva, donde buscar a Dios también entre los cacharros de la cocina y encontrarse a sí misma, para lo que las monjas dispondrían de ámbitos propicios para su privacidad (las «ermitas»). La madre Teresa permitía a sus monjas comer carne y dormir lo necesario para que no dejaran de tener los pies bien afirmados en el suelo. Ella combatió la imagen de la monja ñoña, que vive fuera de la realidad. Sus religiosas debían ser mujeres de carne y hueso; ni más ni menos que eso: personas, que no dejaban de serlo ni por su condición femenina ni por su vida religiosa en comunidad.

Ese espíritu moderno no sobreviene y tampoco se improvisa ni se imposta, sino que es expresión de una mentalidad (madura, añadiríamos), fruto de una formación cualificada, que se traduce en una manera de vida y se manifiesta más específicamente (hablando de religiosos) en una forma personal de vivir la religión, de espiritualidad íntima, ajustada a los principios del innovador humanismo cristiano que irrumpía a la sazón.

\subsection{La adaptación a una época de cambios: de la formación a la obligación}

Los europeos del Quinientos debieron asistir a los cambios radicales de su mundo con una sensación de impotencia que imaginamos muy similar a la que sentimos los ciudadanos de este convulso siglo xxi y la misma incertidumbre sobre a dónde conducirían tantas novedades. El mundo, eso sí, se estaba haciendo entonces más grande, mientras que hoy la globalización lo jibariza. Pero entonces, como ahora, el recurso más eficaz para intentar sobrevivir al cambio es la versatilidad y esa capacidad de adaptación a lo nuevo solo la proporciona la madurez cultural, que no consiste tanto en acumular saberes memorizados como en la aptitud y actitud intelectuales para asumir lo distinto y alcanzar a aceptar la diferencia. No hablamos de «formación académica» sino de «predisposición vital», de cultura en un sentido amplio y no de erudición, de modo que no sabríamos dilucidar cuál de nuestros dos personaje sería más «culto» en este sentido no académico: si el

(C) Ediciones Universidad de Salamanca / ®@ Stud. his., H. ${ }^{a}$ mod., 39, n. 1 (2017), pp. 327-367 
SANTIAGO LA PARRA LÓPEZ

FRANCISCO DE BORJA EN EL ESPEJO DE TERESA DE JESÚS

(VIDAS PARALELAS UNIDAS POR LA MODERNIDAD)

duque-jesuita que se doctoró en Filosofía (aunque fuera «a la borgiana») ${ }^{56}$ o la monja sin formación universitaria pero que acabó siendo proclamada por Pablo VI doctora de la Iglesia Universal (1970).

Es muy conocida la afición de Teresa a la lectura, compaginando libros piadosos con novelas de caballerías. Juan L. Vives desaconsejaba estas lecturas profanas para las mujeres (Insitutio Faeminae Christianae, 1523) y el P. Francisco de Ribera juzgaba que eran instrumento de Satanás, quien se sirve de «hombres vanos» para hacer llegar «estos libros de caballería, sino de vanidades» a aquellas "casas a donde no se da entrada a mujeres perdidas y destruidoras de la castidad $»^{57}$. $\mathrm{Si}$, como afirma E. Bergmann (y no cuestionamos), «la limitación de la lectura femenina a los libros de devoción es mecanismo de control de la imaginación» ${ }^{58}$, parece evidente que esos mecanismos fallaron estrepitosamente con la monja de Ávila, pues no solo frecuentaba la literatura de evasión sino que, como es bien conocido, ella misma comenzó a escribir una novela de caballería junto con su hermano Rodrigo ${ }^{59}$.

$\mathrm{Al}$ ingresar en el convento abandonó este tipo de lecturas profanas: «Diome la vida haber quedado ya amiga de buenos libros. Leía en las Epístolas de San Jerónimo» (Vida, III, 7) ${ }^{60}$. La prohibición inquisitorial de los libros piadosos en lengua vernácula restringió drásticamente su campo de lectura, pues ella no sabía latín: «cuando se quitaron muchos libros de romance, que no se leyesen, yo sentí mucho, porque algunos me daba recreación leerlos y yo no podía ya, por dejarlos en latín» (Vida, xxvi, 5).

Isabel de Borja sí sabía latín cuando ingresó (1510) en el convento gandiense de Santa Clara con solo 13 años. Era hija de María Enríquez y, por tanto, tía de Francisco de Borja. Sirva este dato para ilustrar el ambiente culto que se respiraba en el palacio ducal de Gandia donde nació y creció nuestro protagonista. La

56. Rodrigo Borja (Alejandro VI) consiguió doctorarse en Derecho Canónico en solo poco más de un año en Bolonia (Pavón, M.: "La formación de Alonso y Rodrigo de Borja», en Los Borja. Del mundo gótico al universo renacentista. Valencia, 2001, pp. 115-119). No mucho más tiempo le llevó a su bisnieto Francisco su tesis sobre santo Tomás con la que se doctoró (1550) en la universidad de la Compañía de Jesús fundada por él mismo en Gandia.

57. Ribera, F. de: Vida de santa Teresa..., Lib. I, cap. V, p. 99.

58. Bergmann, E. L.: «La exclusión de lo femenino en el discurso cultural del Humanismo», en Vilanova, A. (dir.): Actas del X Congreso de la Asociación Internacional de Hispanistas. Barcelona, 1992, 2 vols, I, pp. 365-371, cit. de p. 367 (original de 1989).

59. Gagliardi, D.: Urdiendo ficciones: Beatriz Bernal, autoras de caballerías en la España del siglo XVI. Zaragoza, 2010, p. 109.

60. Debe referirse a la traducción de Juan de Molina (1520), dedicada a María Enríquez (Berger, P.: Libro y lectura en la Valencia del Renacimiento. Valencia, 1987, 2 vols., I, 177).

(C) Ediciones Universidad de Salamanca / ®@ Stud. his., H. ${ }^{a}$ mod., 39, n. 1 (2017), pp. 327-367 
SANTIAGO LA PARRA LÓPEZ

FRANCISCO DE BORJA EN EL ESPEJO DE TERESA DE JESÚS

(VIDAS PARALELAS UNIDAS POR LA MODERNIDAD)

formación de Francisco de Borja ${ }^{61}$ respondería perfectamente a las pautas con las que Baltasar Castiglione dibujó el modelo de cortesano en su famoso libro, que sería traducido por Juan Boscán al castellano en 1534 y, por tanto, cabe pensar que en Gandia no se conocía cuando se trató de la educación del futuro IV duque, nacido en 1510.

El Renacimiento se gestó y floreció en las ciudades. El campo era lugar amable e ideal en los versos de una literatura bucólica, cuyos autores desconocían por completo la realidad cotidiana del ámbito rural. No diremos que los humanistas fueran cosmopolitas en el sentido actual del término, aunque el latín facilitaba mucho la relación entre aquellos escritores de diferentes «naciones» (lenguas), que glosaban la vida retirada pero se aburrían en el campo. Jaume Roig, por ejemplo, lo reconocía explícitamente cuando explicaba que escribió (1459-1460) su Llibre de les dones en Callosa d'En Sarrià (a donde llegó huyendo de la peste en Valencia, aunque él era médico) trobant-me en aquesta vall, Callosa, / per les morts fuit I ociós, trist, sense fer fruit...

Santa Teresa amaba la naturaleza pero buscaba las ciudades (pese a su mala experiencia en Sevilla), pues por sus calles pululaban las ideas (no todas ortodoxas), se concitaban pecadores y delincuentes, sí, pero también allí era más fácil encontrar los necesarios mecenas para las fundaciones y oportunidades de todo tipo... «La Madre Teresa era sustancialmente urbana y sus fundaciones fueron proyectadas para ciudades ricas, limosneras, a pesar de que no tardara en acceder a asentamientos en lugares más reducidos» ${ }^{62}$. El profesor Egido sugiere así mismo que la concurrencia de antecedentes judaicos entre los mercaderes facilitaría las relaciones de la santa con estos profesionales y su mundo. Parece un poco forzado el argumento, pero sí parece cierto que «la reforma del Carmelo se produce en un periodo de prosperidad» y esto no pudo ser por casualidad ${ }^{63}$.

Borja nació en Gandia, muy lejos de los centros de poder de su tiempo, pero desde muy temprano desarrolló su vida pública en la corte cosmopolita del emperador y luego llegó a la cima de la orden en la que ingresó cuando se hizo religioso. Borja salió de casa de sus padres siendo poco más que un niño, se pasó el resto de sus días viajando y comenzó su vida pública en contacto con las influencias flamencas y portuguesas de una corte políglota. Su fulgurante ascenso desde la más remota periferia de la monarquía hasta los centros neurálgicos del poder no cabe atribuirlo a la casualidad ni cabe pensar que estuviera al alcance de alguien

61. Cfr. La Parra, S.: «Francisco de Borja y Gandía: la formación del cortesano», en LA Parra, S. y Toldrà, M. (eds.): Francisco de Borja..., p. 83-105.

62. EgIdo, T: “"Mis amigos mercaderes” y gentes...", p. 495.

63. Pérez, J.: Teresa..., 82.

(C) Ediciones Universidad de Salamanca / ®@ Stud. his., H. ${ }^{a}$ mod., 39, n. 1 (2017), pp. 327-367 
SANTIAGO LA PARRA LÓPEZ

FRANCISCO DE BORJA EN EL ESPEJO DE TERESA DE JESÚS

(VIDAS PARALELAS UNIDAS POR LA MODERNIDAD)

aferrado al pasado y acogido a la sombra del campanario de su pueblo. Frente a la imagen difundida del santo duque de Gandia como persona de mentalidad tradicional (y aun «retrógrada»), nosotros creemos que Francisco fue un hombre de mente abierta, requisito imprescindible para una actitud cosmopolita, como evidencia, por ejemplo, la fundación de una Universidad en su ciudad natal, que sería la primera gestionada por los miembros de una orden recién fundada, lo cual no dejaba de ser riesgo añadido a la aventura de crear un centro de enseñanza superior $^{64}$. Ese «espíritu universal» de Francisco de Borja (como lo definió J. Pastor con intención diferente a la nuestra $)^{65}$ se convertiría en exigencia directa en cuanto se hizo cargo de la orden ignaciana, de modo que una de sus últimas decisiones como General de la Compañía debió de ser la evangelización de México, a donde llegaron los primeros misioneros jesuitas el 26 de septiembre de 1572, cuatro días antes del fallecimiento de Borja ${ }^{66}$.

La vivencia cosmopolita de Borja y de la madre Teresa obedece, sin duda, a una inquietud personal, pero se nos antoja más fruto de su respectivo sentido de la obligación que de la mera afición (pues la devoción no se les cuestiona a ninguno de los dos). Tal cual ocurría con sus viajes, que es aspecto muy elocuente de ese cosmopolitismo. Ambos eran espíritus urbanos y los dos se pasaron la vida viajando, aunque a ninguno de ellos les gustaba hacerlo, como era lógico a la sazón. El viaje por gusto es muy reciente y se llama turismo. Viajar es hoy una actividad placentera, que provoca envidia, pero en el Quinientos el viajero todavía suscitaba admiración y se rezaba por él, pues practicaba una actividad de riesgo. Teresa era diestra, por lo visto, cabalgando en mula, pero su medio de transporte más habitual era el carro, que facilitaba la intimidad de las monjas y les permitía no abandonar durante el viaje las prácticas devocionales en aquellos vehículos, «verdaderos conventos ambulantes» ${ }^{67}$. Pero no le gustaba viajar.

64. Esta universidad menor en el plano académico ha sido profusamente estudiada por Pilar García Trobat, a cuyas obras remitimos.

65, Pastor Gómez, J.: Borja espiritu universal (Breve biografía de San Francisco de Borja 1510-1573). Bilbao, 1977, 2. ${ }^{\mathrm{a}}$ ed. (1970).

66. González de Cossío, F. (Prólogo y selección de): Crónicas de la Compañía de Jesús en la Nueva España. México, 1979 (primera reimpresión; ed. original 1957).

67. EgIDO, T: “Mis amigos mercaderes” y gentes...», cit. de p. 491 y pp. 491-493 sobre los avatares de los viajes de la santa por caminos, veredas y vados. El P. Jerónimo Gracián nos dejó algún testimonio de primera mano sobre sus aventuras y desventuras viajeras en su Escolias a la vida de santa Teresa compuesta por el P. Ribera, ed. de Astigarraga, J. L. Roma, 1982, separata de Ephemerides Carmeliticae, 32, pp. 343-430, cit. de p. 413.

(C) Ediciones Universidad de Salamanca / ®@ Stud. his., H. ${ }^{a}$ mod., 39, n. 1 (2017), pp. 327-367 


\section{SANTIAGO LA PARRA LÓPEZ \\ FRANCISCO DE BORJA EN EL ESPEJO DE TERESA DE JESÚS \\ (VIDAS PARALELAS UNIDAS POR LA MODERNIDAD)}

No pongo en estas fundaciones los grandes trabajos de los caminos, con fríos, con soles, con nieves..., porque... de ordinario es tener yo poca salud, sino que veía claro que nuestro Señor me daba esfuerzo. (Libro de las Fundaciones, xviii, 4).

El empleo cortesano de Borja le obligaba a viajar continuamente, de modo que sus hijos fueron naciendo por los diferentes lugares de la geografía española que la familia recorría por razón del cargo paterno: Carlos en Madrid (1530), Isabel en Medina del Campo (1532), Juan en Bellpuig (1533), Álvaro en Toledo (1534/35), Juana (1535/36) y Fernando (1537) de nuevo en Madrid, Dorotea en Valladolid (1538) y Alfonso en Toledo (1539). Esta actividad viajera de Francisco es otra diferencia radical con la forma de vida de su padre y nueva contrariedad añadida a la tesis tradicional (maniquea, en nuestra opinión) que insiste en presentar al III duque de Gandia como adalid del humanismo frente a su hijo y heredero, que supondría un retroceso, una vuelta al pasado en todos los órdenes y particularmente en el de la espiritualidad. El cosmopolitismo de Francisco de Borja contrastaría radicalmente con el sedentarismo a ultranza de su padre, que queda bien reflejado en el contenido de la carta que el propio Francisco de Borja escribió al secretario imperial Francisco de los Cobos con la estratagema que él mismo sugería para vencer la resistencia de su padre a su matrimonio con Leonor de Castro, que había urdido la propia emperatriz. El fragmento fundamental de la misiva en cuestión lo recogía así Dionisio Vázquez:

Mi padre, como nunca salió de su rincón de Gandia, no se amolda a las leyes que corren por acá. Por ventura teme que es contra los Fueros de aquellos reinos de Aragón que yo tome estado fuera de ellos. Mas si Su Majestad es servido que este negocio se pase adelante, yo le abriré el camino llano. Envíe decir a mi padre que, para ciertas cosas de su servicio, le ha menester en esta corte y que luego procure venir a ella. Y con esto alzará el duque (su) mano de mí y dará conmigo también a todos los otros hijos, a trueque de no salir de su quietud ni venir a la corte ${ }^{68}$.

$\mathrm{Ni}$ a la madre Teresa ni al P. Borja les gustaba viajar. Ambos gozaron siempre de una mala salud de hierro. Pero lo cierto es que a ella la muerte la sorprendió fuera de casa, en Alba de Tormes, y a él tras un viaje muy penoso, que acabó medio moribundo y llevado en andas. El P. Borja volvió a Roma de aquel, su último viaje por España y Portugal, en camilla ${ }^{69}$ y la madre Teresa «en sus últimos años, literalmente se fue arrastrando físicamente ${ }^{70}$. Lo hacían porque ellos pensaban,

68. Vázquez, D.: Historia de la vida..., 136.

69. García Hernán, E.: La acción diplomática de Francisco de Borja al servicio del pontificado, 1571-1572. Valencia, 2000.

70. Alabrús, R. M. ${ }^{a}$ y García Cárcel, R.: Teresa..., 87.

(C) Ediciones Universidad de Salamanca / ®@ Stud. his., H. ${ }^{a}$ mod., 39, n. 1 (2017), pp. 327-367 
SANTIAGO LA PARRA LÓPEZ

FRANCISCO DE BORJA EN EL ESPEJO DE TERESA DE JESÚS

(VIDAS PARALELAS UNIDAS POR LA MODERNIDAD)

sencillamente, que era su obligación. Ese sentido de la responsabilidad personal fue uno de los principios que compartieron hasta el final, que sirvió de nexo de unión entre los dos y los situó en el epicentro del tiempo nuevo que ellos vivieron y protagonizaron, que apuntaba en la dirección de valorar a las personas más por sus méritos personales que por el peso de sus apellidos.

\subsection{En la morada del alma: devociones intimas y persecuciones públicas}

Como ya hubiera conocido el propio Ignacio de Loyola, también nuestros dos personajes, sobre todo Borja $a^{71}$, vivieron experiencias religiosas muy rigurosas, excesos penitenciales incluidos, que pronto superaron en aras de una religiosidad más comedida, racional e íntima, más moderada y, en definitiva, tributaria de la devotio moderna, acorde con los principios del humanismo cristiano. A nosotros nos parece que, puestos a elegir, a ambos les seducía mucho más la figura de la contemplativa María, pero los dos hubieron de emplearse a fondo como hacendosas y pragmáticas Martas, si bien acertaron a compatibilizar ambos prototipos vitales. En el propio título del capítulo iv de la Séptima Morada, Teresa proclamaba su convencimiento de que para que fructifiquen en el alma las mercedes que nos hace el Señor «es necesario que anden juntas Marta y María». Y añadía aquí (punto 12): «creedme que Marta y María han de andar juntas para hospedar al Señor y tenerle siempre consigo, y no le hacer mal hospedaje no le dando de comer».

Las hermanas de Lázaro de Betania que agasajaron a Cristo, cada una a su manera (Lucas 10, 38-42), eran modelo recurrente en el Quinientos. Así, por ejemplo, el cardenal Reginald Pole (confidente de María Tudor) le escribía el 16.IX.1555 a Felipe II, esposo de la reina de Inglaterra a la sazón, que ella «pasa las mañanas en oración, como María, y en las tardes sigue admirablemente el ejemplo de Marta despachando asuntos» ${ }^{72}$. Ahora bien, según Elizabeth Rhodes, mientras que Borja aspiraba a ser María y su condición masculina le indujo a ser Marta, a las mujeres de su tiempo les ocurría lo contrario: «a las religiosas les fue prohibida la vida activa y apostólica, precisamente la que muchas de ellas

71. Ruiz Jurado, M.: «Un caso de profetismo reformista en la Compañía de Jesús. Gandía 1547-1549», AHSI, XLIII, fasc. 86, 1974, pp. 217-266; Ryan, M. ${ }^{a}$ P.: El jesuita secreto: San Francisco de Borja. Valencia, 2008, pp. 143-160. El propio José de Calasanz se vería «contaminado» por esta religiosidad rigurosa por influencia del jesuita P. Cordeses, uno de los protagonistas del «caso gandiense» (GINer Guerri, S.: San José de Calasanz. Maestro y fundador. Nueva biografía crítica. Madrid, 1992, pp. 331-336).

72. Cit. por Parker, G.: Felipe II. La biografía definitiva. Barcelona, 2010, p. 127.

(C) Ediciones Universidad de Salamanca / ®@ Stud. his., H. ${ }^{a}$ mod., 39, n. 1 (2017), pp. 327-367 
SANTIAGO LA PARRA LÓPEZ

FRANCISCO DE BORJA EN EL ESPEJO DE TERESA DE JESÚS

(VIDAS PARALELAS UNIDAS POR LA MODERNIDAD)

anhelaban y la que, irónicamente, tanto cansaba a Francisco de Borja» ${ }^{73}$. Parece claro, pues, que el continuo ir y venir de la madre Teresa tampoco se ajustó, según esto, a lo que de ella se esperaba.

Pero el anhelo de aunar esas dos actitudes ejemplares, modélicas en su tiempo, no ha sido bien entendido siempre, comenzando en ocasiones por los «de casa», cuyas dudas son las que más duelen. De hecho, la íntima experiencia mística teresiana ha sido objeto, víctima más bien, de vulgarizaciones muy desafortunadas, cuando no abiertamente groseras, con la vitola de diagnósticos psiquiátricos extemporáneos y muy osados, realizados sin conocer a la paciente. Así mismo, la tendencia contemplativa de Borja, que para la madre Teresa resultaba admirable, acabaría volviéndose contra el duque-jesuita (incluso dentro de su propia orden), de modo que el P. Dalmases se vio en la necesidad de aclarar que Borja no estaba neurótico, que era «un sujeto completamente normal» ${ }^{74}$. La mística se movía por el estrecho filo de la navaja entre la discutida ortodoxia erasmista y la condenada heterodoxia, tanto culta (luterana) como la más vulgar iluminista. Según Alabrús y García Cárcel, las diferencias entre estas corrientes espirituales se les escapaban a los coetáneos del común, quienes las veían como un «totum revolutum» ${ }^{75}$.

Bien sea por las dificultades para diferenciar entre esas prácticas, por la condena expresa del «quietismo» y los excesos cometidos por determinados iluminados e iluminadas o por todo ello junto, que es lo más probable, lo cierto es que la acusación de iluminismo contra Borja ha estado más o menos latente, pero ha estado, como lo prueba el expreso y tajante rechazo de esta desviación que hacía el P. GarcíaVilloslada a favor del duque de Gandia ${ }^{76}$. Según Bataillon, «los jesuitas supieron liberarse muy pronto de la sospecha de iluminismo que suscitaba la exaltación de la fe y de la gracia» y precisaba que fue Laínez quien «salvó [a la Compañía] de esta torpeza» ${ }^{77}$. Para J. L. González Novalín, en fin, Borja no solo estaría muy lejos del iluminismo, sino que fue «la figura valenciana más representativa del siglo

73. Rhodes, E.: «Las vidas de Francisco de Borja y las normas del género», en García Hernán, E. y Ryan, M. P. P. (eds.): Francisco de Borja y su tiempo (1510-1572). Política, religión y cultura en la Edad Moderna. Valencia-Roma, 2011, pp. 681-687, cit. de p. 686.

74. «Si la confusión de Borja no ha de ponerse en relación con los escrúpulos, menos cabe explicarla por un sentimiento morboso, propio de los neuróticos. En Borja no descubrimos el complejo de culpa. Psicológicamente nos parece un sujeto completamente normal» (DALMASES, C.: «El sentimiento de confusión en san Francisco de Borja», Manresa, XXXIV, n. ${ }^{\circ} 131,1962$, pp. 99-118, cit. de p. 116).

75. Alabrús y García Cárcel: Teresa..., 166.

76. García-Villoslada, R.: Loyola y Erasmo. Dos almas, dos épocas. Madrid, 1965, nota 23, p. 93.

77. Bataillon, M.: Erasmo y España. Estudios sobre la bistoria espiritual del siglo XVI. México, 1966, 2. ${ }^{a}$ ed., p. 752 (orig. en francés: 1937).

(C) Ediciones Universidad de Salamanca / ®@ Stud. his., H. ${ }^{a}$ mod., 39, n. 1 (2017), pp. 327-367 
SANTIAGO LA PARRA LÓPEZ

FRANCISCO DE BORJA EN EL ESPEJO DE TERESA DE JESÚS

(VIDAS PARALELAS UNIDAS POR LA MODERNIDAD)

de oro» $\mathrm{y}$ «uno de los artífices de la Contrarreforma», en tanto que protagonista fundamental «en la instauración del humanismo postridentino» ${ }^{78}$.

Es bien conocido el aire erasmista que se respiraba en la Gandia que vio nacer a Francisco, donde creció y aprendió las primeras letras. Pastor Zapata ya demostró que el holandés era el autor más repetido en la bien nutrida biblioteca del III duque de Gandia ${ }^{79}$. Pons Fuster ha estudiado la generosa protección que D. Juan de Borja (amigo de J. L. Vives, como ya hemos dicho) brindó a Bernardo Pérez de Chinchón, el mayor traductor de Erasmo al castellano en el Quinientos, quien murió en Gandia siendo canónigo de su colegiata ${ }^{80}$. Este autor llega a una conclusión ecléctica, según la cual el erasmismo inicial del III duque se teñiría de iluminismo con el lego franciscano Juan de Texeda, quien en 1543 llegó a Gandia, procedente de Barcelona en el séquito del IV duque, Francisco, de modo que «erasmismo e iluminismo... acabaron fundiéndose» en la Gandia de los Borja... ${ }^{81}$.

En 1557 el P. Francisco le pareció a Teresa «un gran contemplativo». Pero antes, durante su gobierno como duque (1543-1550), «convirtió Gandia en una especie de santuario de espiritualidad...» ${ }^{82}$, más cercana al rigor franciscano que a la racionalidad erasmista. La estricta moralidad que comenzaba por exigirse a sí mismo la hizo extensible -más moderada- a su familia y vasallos para que fueran cristianos devotos y personas honradas. En la cornisa del «Salón de Coronas» (estancia que el duque Francisco añadió al palacio ducal gandiense) mandó escribir (inspirándose en San Pablo: 1 Cor. 9, 24 y 2 Tim. 2, 5) para perpetuo recuerdo de sus hijos: Sic currite ut comprehendatis quia non coronabitur nisi que legitime certaverit $^{83}$. El 25.VI.1567, siendo ya General de la Compañía, le escribían sus

78. González Novalín, J. L.: «Francisco de Borja, duque de Gandía. Su presencia y aportación a la Contrarreforma en España», en Arnau-García, R. y Ortuño Soriano, R. (coords.): "Cum vobis et pro vobis». Homenaje de la Facultad de Teologia... al... Dr. D. Miguel Roca Cabanellas... Valencia, 1991, pp. 675-693, cit. de p. 675 y 676. Cfr. Navarro Sorní, M.: «La espiritualidad valenciana del siglo xvi y san Francisco de Borja», en García Hernán, E. y Ryan, M. ${ }^{a}$ P. (eds.): Francisco de Borja y su tiempo..., pp. 669-679 y Pons Fuster, F.: Erasmistas, mecenas y humanistas en la cultura valenciana de la primera mitad del siglo XVI. Valencia, 2003.

79. Pastor Zapata, J. L.: «La biblioteca de Don Juan de Borja Tercer Duque de Gandía $(† 1543) »$, AHSI, LXI, 1992, pp. 275-308.

80. Pons Fuster, F.: «Bernat Pérez (de Chinchón). Un erasmista en la Cort dels Borja a Gandia», Afers. Fulls de recerca $i$ pensament, 23/24, 1996, pp. 153-176 y «Nuevas aportaciones biográficas sobre el maestro Bernardo Pérez de Chinchón», Escritos del Vedat, vol. XXXIII, 2003, pp. 329-367.

81. Pons Fuster, F.: «El mecenazgo cultural de los Borja de Gandía: erasmismo e iluminismo», Estudis, 21, 1995, pp. 23-43, cit. de p. 43.

82. Pons Fuster, F.: «El mecenazgo...», p. 35.

83. Cervós, F. y Solá, J. M.a: El palacio ducal de Gandía..., p. 82.

(C) Ediciones Universidad de Salamanca / ®@ Stud. his., H. ${ }^{a}$ mod., 39, n. 1 (2017), pp. 327-367 
hermanas María e Isabel, ambas monjas en Santa Clara de Gandia (Sor María de la Cruz y Sor Juana Bautista, respectivamente), dando por supuesto su enorme satisfacción al hacerle saber el gran éxito de la predicación del jesuita Juan Bautista Sánchez, pues los gandienses «han dexado juegos, bayles y vanidades y, en lugar desto, an tomado disciplinas, cilicios y penitencias» ${ }^{84}$.

La trayectoria espiritual de la madre Teresa debió ser muy parecida a la de su admirado Borja, pues según el P. Melquiades Andrés, ella maduró «en el ambiente de oración mental metódica, de mística del recogimiento, de evangelismo erasmista, de estima de la perfección y del rigor» propio de su tiempo, por cuanto «ella no puede ser entendida de espaldas a su época. Esta, a su vez, queda desvalorizada sin aquélla» ${ }^{85}$. Y tampoco la santa abulense se libró de las sospechas inquisitoriales de iluminismo, acusación que servía también como excusa idónea para combatir la aspiración de autonomía personal que ella quería para sus monjas, su reivindicación de la devoción personalizada, en general, y de la oración mental, en particular ${ }^{86}, y$, en definitiva, de hacer del Carmelo una forma de vida comunitaria para mujeres de carne y hueso, consagradas por entero a Dios.

Borja, como es bien sabido, fue incluido en el Índice de Valdés (1559), junto con otros nombre ilustres, como Fr. Luis de Granada, Juan de Ávila o el arzobispo Carranza, pero no Teresa de Jesús, quien nunca fue procesada por el Santo Oficio (gracias, acaso, al cardenal inquisidor Quiroga), aunque sus Meditaciones acabaron en la hoguera inquisitorial por las intrigas y maquinaciones de la caprichosa princesa de Éboli ${ }^{87}$. El procesamiento de Borja fue un error (consecuencia de la avidez de un impresor avispado), pero le costó un enorme disgusto al interesado y meses de un prudente exilio voluntario en Portugal ${ }^{88}$. Santa Teresa, como decimos, no

84. Monumenta Historica Societatis Iesu. Sanctus Franciscus Borgia, quartus Gandiae dux et Societatis Iesu Praepositus Generalis tertius, vol. IV (1565-1568). Madrid, 1911, p. 484.

85. ANDRÉs Martín, M.: «Pensamiento teológico y vivencia religiosa en la Reforma española (1400-1600)», en García-Villoslada, R.: Historia de la Iglesia en España, vol. III-2 Iglesia en la España de los siglos XV y XVI (dir. por González Novalín, J. L.). Madrid, 1980, pp. 269-361, cit. de p. 356. De este autor: Historia de la mística de la edad de oro en España y América. Madrid, 1994.

86. «La reforma carmelitana es, en realidad, un refugio que Santa Teresa y sus compañeros edifican para la oración mental amenazada» (BATAillon, M.: Erasmo..., 750).

87. Llamas Martínez, E.: Santa Teresa de Jesús y la Inquisición española. Madrid, 1972.

88. Dalmases, C.: «San Francisco de Borja y la Inquisición española, 1559-1561», AHSI, XLI, fasc. 81, 1972, pp. 48-135; CerecedA, F.: «Episodio inquisitorial de san Francisco de Borja», Razón y Fe. Revista Hispano-Americana de Cultura, 142, 1950, pp. 174-191 y 355-366; n. 143,1951 , pp. 277-291; García Hernán, E. (ed.): Monumenta Borgia VII (1550-1566). Sanctus Franciscus Borgia, quartus Gandiae dux et Societatis Iesu praepositus generalis tertius (1510-1572). Valencia-Roma, 2009. Sobre la vertiente política de este desagradable episodio,

(C) Ediciones Universidad de Salamanca / ®@ Stud. his., H. ${ }^{a}$ mod., 39, n. 1 (2017), pp. 327-367 
llegó a verse empapelada, pero lo cierto es que «sus libros no se publicarán sino después de su muerte» ${ }^{89}$. No sabemos qué es peor, si el procesamiento por error que sufrió Borja o la represión preventiva de la obra teresiana.

Pero no terminarían en 1599 con el error del inquisidor Valdés las afrentas contra Borja y su memoria, pues su vocación contemplativa (tan admirada por la madre Teresa) alimentó ya entre los propios correligionarios de su tiempo las dudas de su fidelidad al espíritu ignaciano (que mucho nos tememos no se hayan disipado del todo dentro de la propia Compañía). El jesuita Benedetto Palmio (Parma, 1523-Ferrara, 1598), poco afecto a Borja y abiertamente contrario a Dionisio Vázquez, se mostraba en su Autobiografía así de tajante:

F. Borgia, ancora que fusse homo e santo, non era così conforme al spiritu d'Ignatio essendo stato ammaestrato del frare Giovanni [Tejeda]... e ciò si vede chiaramente nel suo generalato ${ }^{90}$.

El P. Pastor Gómez abordaría de frente esta cuestión para reafirmar su pleno convencimiento de que «Borja fue un hombre de empresa de extraordinaria actividad externa»y, en definitiva «un perfecto jesuita» ${ }^{91}$. Nosotros estamos convencidos de que el propio Loyola, quien conocía de primera mano las veleidades contemplativas del duque de Gandia y los excesos que llegaron a cometerse en su corte ducal, nunca suscribiría esa «descalificación», pues el fundador sabía muy bien a quién eligió con tanto empeño y no creemos que el elegido llegara a defraudar, ni mucho menos, la confianza depositada en él, como evidencia (valga solo como botón de muestra de lo que decimos) la fundación en Gandia de la primera universidad de la Compañía en Gandia.

\subsection{La Compañia de Jesús, punto de encuentro de Borja y la madre Teresa}

Aunque Carlos I hiciera lo propio al retirarse en el monasterio de Yuste (1556), el emperador nunca acabó de entender las razones de su antiguo cortesano y buen amigo Borja para hacerse religioso, con la duda añadida de haber optado por una orden nueva y, por tanto, sin el prestigio acrisolado de las que ya peinaban canas,

cfr. Martínez Millán, J.: «Familia real y grupos políticos: la princesa doña Juana de Austria (1535-1573)» y de este mismo autor: «En busca de la ortodoxia: el Inquisidor General Diego de Espinosa», ambos en Martínez Millán, J. (dirig. por): La corte de Felipe II. Madrid, 1994, pp. 73-105 y 189-228, respectivamente.

89. Bataillon, M. Erasmo..., p. 750.

90. Cit. por García Hernán, E. (ed.): «Introducción» a Monumenta Borgia VII..., p. 18.

91. Pastor Gómez, J.: Borja espiritu universal..., pp. 154-155.

(C) Ediciones Universidad de Salamanca / ®@ Stud. his., H. ${ }^{a}$ mod., 39, n. 1 (2017), pp. 327-367 
como él decía. El asunto se lo planteó abiertamente a Borja en el primero de sus encuentros extremeños (diciembre de 1556) que, por cierto, no tuvo lugar en Yuste sino en Jarandilla (donde el césar esperaba que terminaran de acondicionar la casa de su retiro). Acompañaban al P. Borja en aquella ocasión Bartolomé Bustamante, el Dr. Herrera y el inseparable hermano Marcos ${ }^{92}$. Así, pues, aunque Dionisio Vázquez no estuvo presente, en el capítulo 22 del Libro Segundo de su biografía trata «de lo que pasó con el emperador sobre su entrada en la Compañía» y muy probablemente la minuciosa crónica de la entrevista que reconstruye aquí no difiera mucho de la conversación real mantenida entre ambos. Según esto, Borja comenzaría reconociendo su inclinación inicial hacia la orden del poverello de Asís, «assí por la antigua devoción de mi casa y padres con este glorioso sancto como porque yo, desde mi niñez, me crié en ella», pero acabaría dejándose llevar por los mensajes que le llegaban directamente del cielo (incluyendo el consejo explícito del propio lego Texeda, intérprete de esos avisos), a lo que se unía la atracción de la juventud de la Compañía. Porque, por una parte, él creía que eso le permitiría pasar más desapercibido en su nueva vida religiosa y, por otra, se le ofrecía como un reto para contribuir a hacer grande la criatura ignaciana. Y Vázquez le atribuía esta reflexión final:

También me combidó a elegir la Compañía que esta religión abraça con el aprovechamiento y bien de los próximos y que tiene los medios muy accomodados para conseguir ambos fines, juntando la vida activa con Martha a la contemplativa de su hermana María ${ }^{93}$.

Mucho se ha especulado sobre las razones del giro copernicano dado a su vida por Francisco de Borja ${ }^{94}$. Nosotros creemos que, además del enorme poder de convicción del P. Fabro y, sobre todo, de Ignacio de Loyola (quien se empleó a fondo para incorporar a sus filas al duque de Gandia), lo que debió acabar por decidir a Borja a hacerse jesuita fue precisamente la modernidad de la Compañía, una orden hija de la imprenta, con formas peculiares (ausencia de la clausura conventual y capítulo comunitario, de hábito propio y oración coral, cuarto voto...) y vocación mesiánica, procurando compaginar acción y contemplación... ${ }^{95}$.

92. Alcázar, B.: Chrono-bistoria de la Compañia de Jesús en la provincia de Toledo y elogio de sus varones illustres, fundadores, bienhechores, fautores e hijos espirituales. Madrid, 1710 (vols. I-II) y 1712 (vols. III-IV), I, p. 335.

93. VÁzquez, D.: Historia de la vida..., pp. 284-287.

94. Ruiz Jurado, M.: «La entrada del Duque de Gandía en la Compañía de Jesús», Manresa, 44, 1972, pp. 121-144.

95. Cfr. nuestro «Estudio introductorio» a VÁzquez, D.: Historia de la vida... También Egido López, T., Burrieza Sánchez, J. y Revuelta GonzÁlez, M.: Los jesuitas en España

(C) Ediciones Universidad de Salamanca / ®@ Stud. his., H. ${ }^{a}$ mod., 39, n. 1 (2017), pp. 327-367 
La madre Teresa pudo perfectamente conocer pronto a los primeros jesuitas llegados a su Ávila natal, pues el polémico colegio de San Gil, que tanto costara acabar de fundar, estaba a una calle de la casa de doña Guiomar de Ulloa, íntima amiga suya. A mayor abundamiento, don Fernando Álvarez del Águila, el benefactor del colegio (que se haría jesuita tras enviudar) era «pariente de parientes» de la santa -como decía ella misma- pues doña Catalina del Águila, prima de él, estaba casada con don Pedro de Cepeda, tío de ell ${ }^{96}$. Pero fueron Gaspar de Daza y Francisco de Salcedo (esposo de Dña. Mencía A. del Águila y, por tanto, cuñado de D. Fernando) quienes la animaron a contactar con aquellos nuevos padres ${ }^{97}$. La santa agradeció expresamente a Gaspar Daza (prebendado en la catedral de Ávila y famoso predicador) que le hubiera facilitado conocer y tratar «gente tan santa como la de la Compañía de Jesús» (Vida, xxiII, 9); poco más arriba escribía que «... habían venido aquí los de la Compañía de Jesús, a quien yo -sin conocer a ninguno- era muy aficionada, de solo saber el modo que llevaban de vida y oración» (Ibid., 3).

Más allá de algún pequeño malentendido (como aquel famoso no borrado intencionadamente), las relaciones de Teresa con la Compañía fueron muy cordiales. De hecho, ella misma le reconocería por carta a su íntimo amigo el P. Jerónimo Gracián ${ }^{98}$ que los «teatinos» (sic) «han sido la principal ayuda que he tenido y jamás lo dejaré de reconocer» ${ }^{99}$. Y esto pese a actitudes misóginas, muy de la época, como la del Visitador Avellaneda, quien aconsejaba a Baltasar Álvarez (rector de Salamanca) «no gastar tiempo con mujeres, especialmente monjas carmelitas, en visitas y por carta... [pues resulta] suaviter et efficaciter irse soltando dellas» ${ }^{100}$.

No cabe pensar que la monja abulense se acercara a la Compañía por la polémica tolerancia de la orden ignaciana para con la exigencia de limpieza de

y en el mundo hispánico. Madrid, 2004 y Burrieza, J.: «La Compañía de Jesús y la defensa de la monarquía hispánica», Hispania Sacra, LX:121, 2008, pp. 181-229.

96. Risco, A.: «Una opinión sobre los tres primeros confesores de Santa Teresa de Jesús (Cetina, Prádanos, B. Álvarez) (conclusión)», $B R A H$, tomo 81, 1922, pp. 41-52, cit. de p. 42.

97. EgIDo, T.: «La principal ayuda...», p. 8.

98. J. Gracián (1545-1614), el carmelita cómplice de santa Teresa, era hijo de un secretario de Carlos V y nieto materno del humanista polaco Juan Dantisco. Erasmista tardío de vida azarosa (el nuevo Lutero, según el nuncio), fue capturado por los turcos y vio cómo su obra reformadora era tumbada por el genovés Nicolás Jesús María Doria en cuanto resultó designado provincial, tres años después de morir Teresa (Ros, C.: Jerónimo Gracián, el amigo de Teresa de Jesús. Burgos, 2014).

99. Astigarraga, J. L.: «Las Cartas de Santa Teresa a Jerónimo Gracián», Ephemerides Carmeliticae, 29, 1978, pp. 149-150.

100. Iglesias, I.: «Santa Teresa de Jesús...», p. 302.

(C) Ediciones Universidad de Salamanca / ®@ Stud. his., H. ${ }^{a}$ mod., 39, n. 1 (2017), pp. 327-367 
SANTIAGO LA PARRA LÓPEZ

FRANCISCO DE BORJA EN EL ESPEJO DE TERESA DE JESÚS

(VIDAS PARALELAS UNIDAS POR LA MODERNIDAD)

sangre ${ }^{101}$ ni tampoco, desde luego, por la influencia directa de Borja, pues ella trató con jesuitas, incluso en el confesionario, antes de conocer al duque de Gandia. Aunque la formación de la madre Teresa (como la de Borja, quien debía hasta su antropónimo al franciscanismo) era deudora de los hermanos menores, sus confesores fueron preferentemente dominicos y jesuitas, pues ella procuró diversificar el control de su conciencia. Su primer confesor jesuita fue el joven e inexperto conquense Diego de Cetina (1531-1568), quien solo cumplió este íntimo cometido durante unos meses de 1555; doña Guiomar de Ulloa (rica toresana, viuda muy joven del abulense D. Francisco Dávila, señor de Salobralejo) le recomendó a su propio confesor, el P. Juan de Prádanos ( I 529-I 597), quien asistió a Teresa entre 1555 y 1558; finalmente, el P. Baltasar Álvarez, además de confesor del poderoso marqués de Velada ${ }^{102}$, oyó los pecados de la santa durante los seis años siguientes ${ }^{103}$. Según Bataillon, «sus confesores jesuitas la encaminarán por una vía de oración metódica y de ascetismo moderado», del que hasta entonces había permanecido muy alejada ${ }^{104}$.

Las fundaciones de la santa estrecharon sus relaciones con quienes popularmente eran conocidos, a la sazón, como «teatinos» ${ }^{105}$. Los jesuitas colaboraron muy estrechamente en las dos primeras (Medina del Campo y Malagón), en la de Toledo (por medio del P. Pablo Hernández) y la de Caravaca (que la santa tuvo siempre como propia, aunque realmente no fuera ella quien la fundara); el

101. Medina, F. de B.: «Ignacio de Loyola y la 'limpieza de sangre'», en Plazaola, J. (ed.): Ignacio de Loyola y su tiempo. Congreso Internacional de Historia (9-13 septiembre 1991). Bilbao, 1992, pp. 579-615. Robert A. Maryks titula un epígrafe «Francisco de Borja's Infinite Love of Conversos» (pp. 100-115) y habla explícitamente de un verdadero grupo de presión judío («New Christian Lobby») en torno a Borja durante el generalato de Laínez, quien era de origen converso. (The Jesuit Order as a Synagogue of Jews. Jesuits of Jewish Ancestry and Purity-of-Blood Laws in the Early Society of Jesus. Leiden-Boston, 2010).

102. Martínez Hernández, S.: «Semblanza de un cortesano instruido: el Marqués de Velada, ayo del Príncipe Felipe (III), y su biblioteca», Cuadernos de Historia Moderna, 22, 1999, pp. 53-78. La relación del P. Álvarez con la madre Teresa no ayudó a disipar las sospechas del «espantajo del iluminismo» que se levantaron contra él dentro de la propia Compañía (BATAIllon. M.: Erasmo..., p. 752).

103. Gómez Centurión, J.: «El padre Diego de Cetina, primer confesor jesuita de Santa Teresa de Jesús», Boletín de la Real Academia de la Historia (BRAH), 71, 1917, pp. 246-253; Risco, A.: «Una opinión sobre los tres primeros confesores de Santa Teresa de Jesús (Cetina, Prádanos, B. Álvarez), $B R A H, 80$, mayo 1922, pp. 462-469, que continúa en: «Una opinión sobre... (conclusión)», BRAH, 81, julio 1922, pp. 41-52.

104. Bataillon, M.: Erasmo..., p. 602.

105. Según el P. B. Alcázar, esa identificación sería inicialmente un error propio «del vulgo de los necios», pero luego se mantuvo "por escarnio», a instancia del cardenal Silíceo, arzobispo de Toledo y gran enemigo de la Compañía, en cuya archidiócesis comenzó a darse esta extendida confusión (Chrono-bistoria..., I, p. 188).

(C) Ediciones Universidad de Salamanca / ®@ Stud. his., H. ${ }^{a}$ mod., 39, n. 1 (2017), pp. 327-367 
P. Jerónimo Ripalda, autor del famoso catecismo, le ayudó a disipar las dudas que tenía sobre abrir casa en Palencia (1580) y así mismo la Compañía echó una mano en la de Burgos el año 1582, seis meses antes de morir Teresa ${ }^{106}$. En el caso de Salamanca esa ayuda no fue solo moral, pues los jesuitas estuvieron trabajando toda una noche en adecentar el inmueble que los anteriores inquilinos, estudiantes, habían dejado inhabitable ${ }^{107}$.

En el proceso de beatificación de la santa abulense se contabilizan más testimonios a su favor de jesuitas que de dominicos (14 frente a 5, respectivamente), pero nada de esto debe hacernos perder de vista que también surgieran algunos problemas. Conocido su mal carácter, no debemos magnificar la ya apuntada falta de sintonía con Dionisio Vázquez. Alabrús y García Cárcel reseñan que «en los últimos meses de vida de Teresa la vieja amistosa relación con la Compañía se trocó en conflictiva», pero concluyen salomónicamente que «es patente que la vinculación de Teresa con los jesuitas pasa por fluctuaciones diversas y, desde luego, nunca apostó incondicionalmente por ellos» ${ }^{108}$. Bien mirado, la santa abulense no apostó incondicionalmente ni por su propia orden, pues su compromiso total era con Dios.

Miguel Mir sí parece que hiciera especial hincapié en los roces de Teresa con la Compañía. Según el académico exjesuita, los Ejercicios ignacianos no tenían nada que ver con la espiritualidad de la madre Teresa y, aparte pequeñas discrepancias, su relación personal con el Provincial Juan Suárez fue muy tensa, pues este culpaba a la monja de que el P. Gaspar de Salazar quisiera dejar la Compañía para hacerse carmelita. Zugasti replicará rotundamente, basándose en hallazgos del P. Leonardo Cross, que «el Padre Gaspar de Salazar jamás trató de separarse de la Compañía de Jesús para pasar a la reforma carmelitana» ${ }^{109}$, aunque sí es cierto que en la Compañía llegó a creerse en algún momento que había solicitado la dispensa para hacerse carmelita, lo que dio origen al intercambio epistolar entre el Provincial Suárez y la madre Teresa.

106. Pérez, J.: Teresa..., pp. 83-103. La fundación de Burgos en Zugasti, J. A.: Santa Teresa..., Bilbao, pp. 80-97.

107. EgIDo, T: «Mis amigos mercaderes» y gentes...», p. 488.

108. Alabrús y García CÁrcel: Teresa..., pp. 197 y 198, respectivamente.

109. Zugasti, J. A.: Santa Teresa..., Bilbao, p. 46; en cursiva en el original; transcribe a continuación, como documento probatorio de su aserto, la carta manuscrita del P. Salazar al P. General Everardo Mercuriano, escrita en Córdoba el 3.IX.1579 (pp. 47-48 y facsímil de la carta en apéndice, $s / n$ ). El autor dedica toda la segunda parte de esta obra (pp. 45-69) a lo que él denomina «El asunto del P. Gaspar de Salazar».

(C) Ediciones Universidad de Salamanca / ®@ Stud. his., H. ${ }^{a}$ mod., 39, n. 1 (2017), pp. 327-367 
SANTIAGO LA PARRA LÓPEZ

FRANCISCO DE BORJA EN EL ESPEJO DE TERESA DE JESÚS

(VIDAS PARALELAS UNIDAS POR LA MODERNIDAD)

\section{Conclusión}

Tenía razón Pierre Suau cuando afirmaba que «pocos santos han sido tan desfigurados como Francisco de Borja» ${ }^{110}$, aunque probablemente nuestros argumentos para revisar a fondo la biografía del santo duque gandiense sean diferentes de los del historiador francés, cuya biografía borgiana ha resistido bien el paso del tiempo. Contra otras opiniones (que nos llegan incluso desde dentro de la propia orden ignaciana), nosotros estamos plenamente convencidos de que el P. Borja en momento alguno traicionó el espíritu ignaciano; muy al contrario, fue decisivo para afianzar la Societas Iesu cuando esta daba sus primeros pasos, lógicamente vacilantes, gracias (entre otras razones) a sus privilegiadas relaciones con Paulo III, quien nunca olvidó que debía su capelo cardenalicio a Alejandro VI, bisabuelo del duque de Gandia (y amante, a la sazón, de Julia Farnese, hermana del papa de Trento).

Abundando en la necesidad de esa revisión a fondo, ya hemos explicado que Francisco de Borja no solo no se desentendió de sus polémicos familiares (como se viene repitiendo) sino que precisamente él impuso en su familia una actitud de expreso reconocimiento y agradecimiento al papa Alejandro VI, verdadero fundador del ducado de Gandia ${ }^{111}$. En consecuencia, el duque-jesuita no puede ser considerado, se mire como se mire, expiador de los pecados familiares, como pretendía con poco acierto Saint Paulien ${ }^{112}$, pseudónimo del jesuita ultramontano Maurice-Yvan Picard.

Y al observar, ahora y aquí, la imagen de Borja reflejada en el alma-espejo de Teresa de Jesús, no nos hemos encontrado con la figura de una persona anclada en el pasado, por no decir abiertamente «retrógrada» (como se ha sugerido en más de una ocasión), sino alguien muy diferente, sin duda, a la santa abulense pero que compartía con ella el sentido y la práctica de la modernidad. Solo así se explica que alcanzara a ganarse la confianza de un espíritu tan exquisito como el de la madre Teresa.

No podemos dudar de que la relación entre nuestros dos protagonistas satisficiera a ambos. Pero, vista con perspectiva histórica, aquella amistad que se fraguó en Ávila ha servido para enriquecer más la memoria del jesuita que fuera

110. Suau, P.: Historia de S. Francisco de Borja. Tercer General de la Compañía de Jesús (1510-1572). Zaragoza, 1963 (1. a ed. en francés 1905, ampliada en 1910), cit. de p. 173.

111. Cfr. La PARra, S.: «El ducado de Gandía y la memoria familiar...»y, desde otra perspectiva, en «El nacimiento de un señorío singular: el ducado gandiense de los Borja», Revista de Historia Moderna. Anales de la Universidad de Alicante, 24, 2006, pp. 31-66.

112. Saint Paulien: San Francisco de Borja, el expiador. Bilbao, 1963.

(C) Ediciones Universidad de Salamanca / ®@ Stud. his., H. ${ }^{a}$ mod., 39, n. 1 (2017), pp. 327-367 
SANTIAGO LA PARRA LÓPEZ

FRANCISCO DE BORJA EN EL ESPEJO DE TERESA DE JESÚS

(VIDAS PARALELAS UNIDAS POR LA MODERNIDAD)

antes poderoso duque de Gandia que la de aquella humilde monja fundadora, que devino en referencia de la espiritualidad más refinada. En términos coloquiales, fue Borja quien salió ganando.

\section{Bibliografía}

Alabrús Iglesias, R. M.a y García Cárcel, R.: Teresa de Jesús. La construcción de la santidad femenina. Madrid, 2015.

AlCázAr, B.: Chrono-historia de la Compañía de Jesús en la provincia de Toledo y elogio de sus varones illustres, fundadores, bienhechores, fantores e hijos espirituales. Madrid, 1710 (vols. I-II) y 1712 (III-IV).

Alvar Esquerra, A.: La emperatriz. Isabel y Carlos V: amor y gobierno en la corte española del Renacimiento (1503-1539). Madrid, 2012.

Amelang, J. S.: «Los usos de la autobiografía: monjas y beatas en la Cataluña moderna», en Amelang, J. S. y Nash, M. (eds.): Historia y Género. Las mujeres en la Europa Moderna y Contemporánea. Valencia, 1990, pp. 191-212.

Andrés Martín, M.: «Pensamiento teológico y vivencia religiosa en la Reforma española (1400-1600)», en García-Villoslada, R.: Historia de la Iglesia en España, vol. III-2: La Iglesia en la España de los siglos XV y XVI (dir. por GonZÁlez Novalín, J. L.). Madrid, 1980, pp. 269-361.

Andrés Martín, M.: Historia de la mística de la edad de oro en España y América. Madrid, 1994.

Astigarraga, J. L.: «Las Cartas de Santa Teresa a Jerónimo Gracián», Ephemerides Carmeliticae, 29, 1978, pp. 149-150.

BataIllon, M.: Erasmo y España. Estudios sobre la historia espiritual del siglo XVI. México, 1966, 2. ${ }^{a}$ ed., (orig. en francés: 1937).

Batllori, M.: «Carlos V y la Compañía de Jesús», Estudios Carolinos. Cuarto centenario del emperador Carlos V. Curso de conferencias (octubre-diciembre 1958), 1959, pp. 133-148.

BATLlori, M.: «El llinatge Borja del segle XIII al XvI», en La família Borja (Obra Completa, IV). Valencia 1994, pp. 3-54 (texto de 1972).

BATLlori, M.: A través de la bistòria i la cultura. Barcelona, 1979.

Berger, P.: Libro y lectura en la Valencia del Renacimiento. Valencia, 1987, 2 vols.

BERGMANN, E. L.: «La exclusión de lo femenino en el discurso cultural del Humanismo», en Vilanova, A. (dir.): Actas del X Congreso de la Asociación Internacional de Hispanistas (Barcelona, 1989). Barcelona, 1992, 2 vols, I, pp. 365-371.

Burrieza Sánchez, J.: «La Compañía de Jesús y la defensa de la monarquía hispánica», Hispania Sacra, LX-121, 2008, pp. 181-229.

Castiglione, B.: El cortesano. Madrid, 1984, 5. ed., reproduce la traducción de Juan Boscán (1534).

CAstro, A.: Teresa la santa y otros ensayos. Madrid, 1982 (original de 1928-1929, revisado en 1971).

(C) Ediciones Universidad de Salamanca / ®@ Stud. his., H. ${ }^{a}$ mod., 39, n. 1 (2017), pp. 327-367 
SANTIAGO LA PARRA LÓPEZ

FRANCISCO DE BORJA EN EL ESPEJO DE TERESA DE JESÚS

(VIDAS PARALELAS UNIDAS POR LA MODERNIDAD)

Cereceda, F.: «Episodio inquisitorial de san Francisco de Borja», Razón y Fe. Revista Hispano-Americana de Cultura, n. ${ }^{\circ} 142,1950$, pp. 174-191 y 355-366; n. ${ }^{\circ} 143,1951$, pp. 277-291.

Certeau, M. de: La fábula mística. Siglos XVI-XVII. Madrid, 2006 (original en francés 1982).

Certeau, M. de: La debilidad de creer. Buenos Aires y Madrid, 2006 (original en francés 1987).

Cervós, F. y Solá, J. M.a.: El palacio ducal de Gandía. Monografía histórico-descriptiva. Barcelona, 1904 (hay edición facsímil, con prólogo de Revuelta González, M. Gandia, 2004).

Dalmases, C. de: «El sentimiento de confusión en san Francisco de Borja», Manresa, XXXIV, 131, 1962, pp. 99-118.

Dalmases, C. de: «Santa Teresa y los jesuitas. Precisando fechas y datos», Archivum Historicum Societatis Iesu (AHSI), 35, 1966, pp. 347-378.

Dalmases, C. de: «San Francisco de Borja y la Inquisición española, 1559-1561», AHSI, XLI, fasc. 81, enero-junio 1972, pp. 48-135.

Dalmases, C. de: El Padre Francisco de Borja. Madrid, 1983.

EgIdo, T.: «Santa Teresa y su obra reformadora», Historia 16, 78, 1982, pp. 43-50.

Egido, T. (ed.): El linaje judeoconverso de santa Teresa (Pleito de hidalguía de los Cepeda). Madrid, 1986.

Egido, T., Burrieza Sánchez, J. y Revuelta González, M.: Los jesuitas en España y en el mundo bispánico. Madrid, 2004.

EgIDO, T.: «"Mis amigos mercaderes” y gentes del común, colaboradores en las fundaciones de santa Teresa», Revista de Espiritualidad, 71, 2012, pp. 475-499

Egido, T.: «"La principal ayuda que he tenido". Santa Teresa y los de la Compañía de Jesús», Manresa: Revista de Espiritualidad Ignaciana, n. ${ }^{\circ}$ 342, vol. 87, 2015, pp. 5-16.

Fernández Álvarez, M.: Carlos V, el César y el hombre. Madrid, 1999.

Fita Colomé, F.: «Cuatro biógrafos de Santa Teresa en el siglo xvi: El Padre Francisco de Ribera, Fr. Diego de Yepes, Fr. Luis de León y Julián de Ávila», BRAH, 67, 1915, pp. 550-561.

Gagliardi, D.: Urdiendo ficciones: Beatriz Bernal, autoras de caballerias en la España del siglo XVI. Zaragoza, 2010.

Gangotena y Jijón, C. de: Genealogía de la Casa de Borja. Quito, 1932.

García de la Concha, V.: «Un nuevo estilo literario», Historia 16, 78, 1982, pp. 51-58.

García Hernán, E.: La acción diplomática de Francisco de Borja al servicio del pontificado, 1571-1572. Valencia, 2000.

García Hernán, E.: «Algunos aspectos de la biografía de san Francisco de Borja», en Callado Estela, E. (coord.): Valencianos en la Historia de la Iglesia. Valencia, 2008, 2 vols; II, 11-135.

García Hernán, E. (ed.): Monumenta Borgia VII (1550-1566). Sanctus Franciscus Borgia, quartus Gandiae dux et Societatis Iesu praepositus generalis tertius (1510-1572). Valencia-Roma, 2009.

(C) Ediciones Universidad de Salamanca / ®@ Stud. his., H. ${ }^{a}$ mod., 39, n. 1 (2017), pp. 327-367 
SANTIAGO LA PARRA LÓPEZ

FRANCISCO DE BORJA EN EL ESPEJO DE TERESA DE JESÚS

(VIDAS PARALELAS UNIDAS POR LA MODERNIDAD)

García Hernán, E. y Ryan, M. ${ }^{a}$ P. (eds.): Francisco de Borja y su tiempo (1510-1572). Política, religión y cultura en la Edad Moderna (Actas del Simposio Internacional, Valencia 2010). Valencia-Roma, 2011, pp. 669-679.

García Mahíques, R.: «El concepto icónico de san Francisco de Borja, elaborado por los jesuitas a partir de la adquisición del palacio ducal de Gandía», en LA PARra, S. y Toldrà, M. (eds.): Francisco de Borja..., pp. 497-516.

García-Villoslada, R.: Loyola y Erasmo. Dos almas, dos épocas. Madrid, 1965.

Giner Guerri, S.: San José de Calasanz. Maestro y fundador. Nueva biografía crítica. Madrid, 1992.

Gómez Centurión, J.: «El padre Diego de Cetina, primer confesor jesuita de Santa Teresa de Jesús», Boletín de la Real Academia de la Historia, 71, 1917, pp. 246-253.

González de Cossío, F. (Prólogo y selección de): Crónicas de la Compañía de Jesús en la Nueva España. México, 1979, 1. a reimpresión (ed. original 1957).

González Novalín, J. L.: «Francisco de Borja, duque de Gandía. Su presencia y aportación a la Contrarreforma en España», en Arnau-García, R. y Ortuño Soriano, R. (coords): «Cum vobis et pro vobis». Homenaje de la Facultad de Teología... al... Dr. D. Miguel Roca Cabanellas... Valencia, 1991, pp. 675-693.

Gracián, J.: Escolias a la vida de santa Teresa compuesta por el P. Ribera, ed. de AstigarRAGA, J. L. Roma, 1982 (Separata de Ephemerides Carmeliticae, 32, pp. 343-430).

Hermann-Röttgen, M.: La familia Borja. Historia de una leyenda. Valencia, 1994 (original en alemán, 1992).

Iglesias, I.: «Santa Teresa de Jesús y la espiritualidad ignaciana», Manresa, 54, 1982, pp. 291-313.

Imícoz Beunza, J. M.: «Transformaciones del vínculo social. Una reflexión sobre los procesos de la modernidad», en Franco Rubio, G. y Pérez Samper, M. a A. (eds.): Herederas de Clío. Mujeres que han impulsado la Historia. Madrid, 2014, pp. 277-296.

Jorge, E.: «San Francisco de Borja y Santa Teresa de Jesús», Manresa, 178, 1974, pp. 43-64.

Kelly, J.: «¿Tuvieron las mujeres Renacimiento?», en Amelang, J. S. y Nash, M. (eds.): Historia y Género. Las mujeres en la Europa Moderna y Contemporánea. Valencia, 1990, pp. 93-126.

KInG, M. L.: Mujeres renacentistas. La búsqueda de un espacio. Madrid, 1993 (original en inglés 1991).

La Parra López, S.: «La mirada sobre los Borja. (Notas críticas para un estado de la cuestión)", Revista de Historia Moderna. Anales de la Universidad de Alicante, 15, 1996, pp. 387-401.

La Parra López, S.: La ruta valenciana de los Borja. Gandia, 1997.

La PArra López, S.: «El nacimiento de un señorío singular: el ducado gandiense de los Borja», Revista de Historia Moderna. Anales de la Universidad de Alicante, 24, 2006, pp. 31-66.

La Parra López, S.: «El ducado de Gandía y la memoria familiar de san Francisco de Borja», Revista de l'Institut Internacional d'Estudis Borgians, 2: Actes del II Simposi

(C) Ediciones Universidad de Salamanca / ®@ Stud. his., H. ${ }^{a}$ mod., 39, n. 1 (2017), pp. 327-367 
SANTIAGO LA PARRA LÓPEZ

FRANCISCO DE BORJA EN EL ESPEJO DE TERESA DE JESÚS

(VIDAS PARALELAS UNIDAS POR LA MODERNIDAD)

Internacional sobre els Borja (Valencia-Gandia, 2007), ed. electrónica: http://personales.upv.es/slaparr/Artículos/183569-236404-1-PB.pdf

La Parra López, S.: «Enríquez, María» en, Diccionario Biográfico Español, vol. XVII. Madrid, 2011.

La Parra López, S. y Toldrà, M. ${ }^{a}$ (eds.): Francisco de Borja (150-1572), hombre del Renacimiento, santo del Barroco. Gandia, 2012.

La Parra López, S.: «Francisco de Borja y Gandía: la formación del cortesano», en LA PARra, S. y ToldrÀ, M. (eds.):: Francisco de Borja..., pp. 83-105.

Luis de León, Fr.: La perfecta casada (1583). Madrid, 1975, 10. a ed.

Llamas Martínez, E.: Santa Teresa de Jesús y la Inquisición española. Madrid, 1972.

Maio, R. di: Mujer y Renacimiento. Madrid, 1988 (orig. en italiano, 1987).

Martínez Hernández, S.: «Semblanza de un cortesano instruido: el Marqués de Velada, ayo del Príncipe Felipe (III), y su biblioteca», Cuadernos de Historia Moderna, 22, 1999, pp. 53-78.

Martínez Millán, J. (dir.): La corte de Felipe II. Madrid, 1994.

MARtínez Millán, J.: «Familia real y grupos políticos: la princesa doña Juana de Austria (1535-1573)», en Martínez Millán, J.: La corte de ..., pp. 73-105.

Martínez Millán, J.: «En busca de la ortodoxia: el Inquisidor General Diego de Espinosa», en Martínez Millán, J.: La corte de..., pp. 189-228.

MAryks, R. A.: The Jesuit Order as a Synagogue of Jews. Jesuits of Jewish Ancestry and Purity-of-Blood Laws in the Early Society of Jesus. Leiden-Boston, 2010.

Medina, F. de B. de: «Ignacio de Loyola y la 'limpieza de sangre’», en Plazaola, J. (ed.): Ignacio de Loyola y su tiempo. Congreso Internacional de Historia (9-13 septiembre 1991). Bilbao, 1992, pp. 579-615.

Mir, M.: Santa Teresa de Jesús, su vida, su espíritu, sus fundaciones. Madrid, 1912, 2 vols.

Monumenta Historica Societatis Iesu. Sanctus Franciscus Borgia, quartus Gandiae dux et Societatis Iesu Praepositus Generalis tertius, vol. IV (1565-1568). Madrid, 1911.

Muniesa, T.: Vida de la V. y Exma. Sra. D. Luisa de Borja y Aragón, Condesa de Ribagorza... Zaragoza, 1691.

O’Neill, Ch. E. y Domínguez, J. (dirs.): Diccionario Histórico de la Compañia de Jesús. Biográfico-temático. Madrid, 2001, 4 vols.

Ortega y Gasset, J.: «Renacimiento y retorno», en En torno a Galileo. (Esquema de la crisis). Madrid, 1982 (1933).

PArker, G.: Felipe II. La biografía definitiva. Barcelona, 2010.

Pastor Gómez, J.: Borja espíritu universal (Breve biografía de San Francisco de Borja 1510-1573). Bilbao, 1977, 2. a ed. (1970).

Pastor Zapata, J. L.: «La biblioteca de Don Juan de Borja Tercer Duque de Gandía $(† 1543) »$, AHSI, LXI, 1992, pp. 275-308.

Pavón, M.: «La formación de Alonso y Rodrigo de Borja», en Los Borja. Del mundo gótico al universo renacentista. Valencia, 2001, pp. 115-119.

Pérez, J.: Teresa de Ávila y la España de su tiempo. Madrid, 2007.

(C) Ediciones Universidad de Salamanca / ®@ Stud. his., H. ${ }^{a}$ mod., 39, n. 1 (2017), pp. 327-367 
SANTIAGO LA PARRA LÓPEZ

FRANCISCO DE BORJA EN EL ESPEJO DE TERESA DE JESÚS

(VIDAS PARALELAS UNIDAS POR LA MODERNIDAD)

Pons Fuster, F.: «El mecenazgo cultural de los Borja de Gandía: erasmismo e iluminismo», Estudis, 21, 1995, pp. 23-43.

Pons Fuster, F.: «Bernat Pérez (de Chinchón). Un erasmista en la Cort dels Borja a Gandia», Afers. Fulls de recerca i pensament, 23/24, 1996, pp. 153-176.

Pons Fuster, F.: «Nuevas aportaciones biográficas sobre el maestro Bernardo Pérez de Chinchón», Escritos del Vedat, vol. XXXIII, 2003, pp. 329-367.

Pons Fuster, F.: Erasmistas, mecenas y bumanistas en la cultura valenciana de la primera mitad del siglo XVI. Valencia, 2003.

Rey Castelao, O.: «Teresa, patrona de España», Hispania Sacra, LXVII, 136, 2015, pp. 531-573.

Rhodes, E.: «Las vidas de Francisco de Borja y las normas del género», en García Hernán, E. y Ryan, M. ${ }^{a}$ P. (eds.): Francisco de Borja y su tiempo..., pp. 681-687.

Ribera, F. de: Vida de santa Teresa de Jesús, Salamanca, 1590; ed. de Pons, J. Barcelona, 1908; incluye Estudio Preliminar sobre «Santa Teresa, doctora mística» de MARTín, L., pp. 1-59.

Risco, A.: «Una opinión sobre los tres primeros confesores de Santa Teresa de Jesús (Cetina, Prádanos, B. Álvarez), BRAH, n. ${ }^{\circ}$ 80, mayo 1922, pp. 462-469 y n. ${ }^{\circ} 81$, julio 1922, pp. 41-52.

Roig. J.: Llibre de les dones, o Spill (1459-1460). Barcelona, 1928.

Ros, C.: Jerónimo Gracián, el amigo de Teresa de Jesús. Burgos, 2014.

Ruiz Jurado, M.: «La entrada del Duque de Gandía en la Compañía de Jesús», Manresa, 44, 1972, pp. 121-144.

Ruiz Jurado, M.: «Un caso de profetismo reformista en la Compañía de Jesús. Gandía 1547-1549», AHSI, XLIII, fasc. 86, 1974, pp. 217-266.

Ruiz Jurado, M.: «Santa Teresa y los jesuitas», Manresa: Revista de Espiritualidad Ignaciana, LXXXVII, n. ${ }^{\circ}$ 342, 2015, pp. 17-28.

Ruiz-Doménec, J. E.: Observando la Modernidad desde la Edad Media. Valencia, 1999.

Ryan, M. P.: El jesuita secreto: San Francisco de Borja. Valencia, 2008.

Saint Paulien: San Francisco de Borja, el expiador. Bilbao, 1963.

SAlazAr y Acha, J. de: «Una rama subsistente del linaje de Borja en la América española», Boletín de la Real Academia Matritense de Heráldica y Genealogía, 75, 2010, pp. 16-17.

Sánchez Albornoz, C.: España un enigma histórico. Barcelona, 1977, 6. ${ }^{a}$ ed (1956), 2 vols.

SAnchis Sivera, J.: Algunos documentos y cartas privadas que pertenecieron al segundo duque de Gandia don Juan de Borja. Notas para la bistoria de Alejandro VI. Valencia, 1919, ed. facsímil con Estudio Introductorio y notas en valenciano por LA PARRA, S. (revisión lingüística por Garcia, V). Gandia, 2001.

Schultz van Kessel, E.: «Vírgenes y madres entre cielo y tierra. Las cristianas en la primera Edad Moderna», en Duby, G. y Perrot, M (dirs.): Historia de las mujeres, vol. III: Del Renacimiento a la Edad Moderna (coord. por Faroe, A. y Davis, N. Z). Madrid 1992, pp. 167-209 (ed. original en italiano: 1990-92).

(C) Ediciones Universidad de Salamanca / ®@ Stud. his., H. ${ }^{a}$ mod., 39, n. 1 (2017), pp. 327-367 
SANTIAGO LA PARRA LÓPEZ

FRANCISCO DE BORJA EN EL ESPEJO DE TERESA DE JESÚS

(VIDAS PARALELAS UNIDAS POR LA MODERNIDAD)

Suau, P.: Historia de S. Francisco de Borja. Tercer General de la Compañía de Jesús (15101572). Zaragoza, 1963, (1. a ed. en francés: 1905, ampliada en 1910, de la que esta es traducción).

Tapia SÁnchez, S. de: «Ávila, la ciudad que conoció Santa Teresa», Salamanca. Revista de Estudios, 59, 2014, pp. 27-44.

Teresa de Jesús: Obras completas, ed. de E. de la Madre de Dios y O. Steggink. Madrid, 2015.

Vázquez, D.: Historia de la vida del P. Francisco de Borja, Tercero General de la Compañia de Jesús (c. 1586), ed. crítica por La Parra López, S. Gandia, 2012.

Vives, J. L.: De officio mariti (1528) e Institutio foeminae christianae (1523), en Obras completas, ed. de Riber, L. Madrid, 1947 (reimpresión por el Consell Valencià de Cultura, Valencia, 1992), pp. 1.259-1.352 y 985-1.175, respect.

Zugasti, J. A.: Santa Teresa y la Compañía de Jesús (Estudio histórico-crítico). Madrid, 1914.

Zugasti, J. A.: Santa Teresa y la Compañia de Jesús. Bilbao, 1914.

(C) Ediciones Universidad de Salamanca / @@ Stud. his., H. ${ }^{a}$ mod., 39, n. 1 (2017), pp. 327-367 
